\title{
Antioxidant Barrier and Oxidative Damage to Proteins, Lipids, and DNA/RNA in Adrenal Tumor Patients
}

\author{
Barbara Choromańska (D, ${ }^{1}$ Piotr Myśliwiec, ${ }^{1}$ Tomasz Kozłowski, ${ }^{1}$ Magdalena Luba, ${ }^{1}$ \\ Piotr Wojskowicz, ${ }^{1}$ Jacek Dadan, ${ }^{1}$ Hanna Myśliwiec, ${ }^{2}$ Katarzyna Choromańska, ${ }^{3}$ \\ Anna Gibała, ${ }^{3}$ Anna Starzyńska, ${ }^{3}$ Małgorzata Żendzian-Piotrowska, ${ }^{4}$ Anna Zalewska, ${ }^{5}$ \\ and Mateusz Maciejczyk (iD) 4 \\ ${ }^{1}$ Department of General and Endocrine Surgery, Medical University of Bialystok, 24a M. Sklodowskiej-Curie Street, \\ 15-276 Bialystok, Poland \\ ${ }^{2}$ Department of Dermatology and Venereology, Medical University of Bialystok, 14 Żurawia Street, 15-540 Bialystok, Poland \\ ${ }^{3}$ Department of Oral Surgery, Medical University of Gdansk, 7 Dębinki Street, 80-211 Gdansk, Poland \\ ${ }^{4}$ Department of Hygiene, Epidemiology and Ergonomics, Medical University of Bialystok, 2c Mickiewicza Street, \\ 15-233 Bialystok, Poland \\ ${ }^{5}$ Experimental Dentistry Laboratory, Medical University of Bialystok, 24a M. Sklodowskiej-Curie Street, 15-274 Bialystok, Poland
}

Correspondence should be addressed to Mateusz Maciejczyk; mat.maciejczyk@gmail.com

Received 25 February 2021; Revised 25 April 2021; Accepted 21 May 2021; Published 22 June 2021

Academic Editor: Jos L. Quiles

Copyright (c) 2021 Barbara Choromańska et al. This is an open access article distributed under the Creative Commons Attribution License, which permits unrestricted use, distribution, and reproduction in any medium, provided the original work is properly cited.

\begin{abstract}
This study is the first to assess redox balance, glutathione metabolism, and oxidative damage to RNA/DNA, proteins, and lipids in the plasma/serum and urine of patients with adrenal masses. The study included 70 patients with adrenal tumors divided into three subgroups: incidentaloma $(n=30)$, pheochromocytoma $(n=20)$, and Cushing's/Conn's adenoma $(n=20)$, as well as 60 healthy controls. Blood and urine samples were collected before elective endoscopic adrenalectomy. Antioxidant defense capacity was significantly decreased (serum/plasma: superoxide dismutase (SOD), catalase (CAT) and reduced glutathione $(\mathrm{GSH})$, uric acid (UA); urine: SOD, GSH, UA) in patients with adrenal masses. The oxidative damage to proteins (advanced glycation end products (AGE), advanced oxidation protein products (AOPP)) and lipids (lipid hydroperoxides (LOOH), and malondialdehyde (MDA)) was higher in the plasma and urine of these patients. Plasma MDA and DNA/RNA oxidation products, with high sensitivity and specificity, can help to diagnose pheochromocytoma. This biomarker differentiates patients with pheochromocytoma from Cushing's/Conn's adenoma as well as from heathy controls. Plasma RNA/DNA oxidation was also positively correlated with urine metanephrine. Oxidative stress can play a crucial role in adrenal tumors. However, further studies are required to clarify the role of redox signaling in adrenal masses.
\end{abstract}

\section{Introduction}

Adrenal masses are the most common of all tumors in humans $[1,2]$. Most adrenal tumors are benign adenomas found incidentally in imaging studies of the abdominal cavity and commonly defined as adrenal incidentalomas [3, 4]. Although most adrenal gland lesions are benign adrenal cortex tumors and do not secrete hormones, a significant proportion may be hormonally active, and their clinical man- ifestation depends on the type of hormones secreted by the tumor. They can secret glucocorticosteroids (cortisol), leading to Cushing's syndrome and mineralocorticosteroids (aldosterone) and Conn's syndrome [2, 5]. Pheochromocytomas, accounting for approx. 5-7\% of all adrenal tumors, originate from the adrenal medulla and secrete catecholamines [6]. Hormonal overproduction can be associated with severe morbidity and, in some cases, can lead to mortality. Moreover, it was found that the size of the tumor is related to 
the risk of malignancy. Tumors in the size range of 4.1 to 6 $\mathrm{cm}$ have a $6 \%$ malignancy risk, while tumors larger than 6 $\mathrm{cm}$ may be malignant in $25 \%$ of cases [7]. Malignant tumors include adrenocortical carcinoma (rare, though, very aggressive), malignant pheochromocytoma, and metastases. The clinical symptoms of adrenal tumors are not specific, and their diagnosis is often difficult. Therefore, a better to understanding of adrenal tumors' biology could help in search for new diagnostic biomarkers. Due to the variety of adrenal tumors, their pathogenesis is still not fully understood. Probably, genetic determinants play a vital role in the development of adrenal tumors. Known risk factors for adrenal tumor comprise smoking in men and oral hormonal contraceptives in women. The likelihood of adrenal tumors also increases among people with obesity, type 2 diabetes, and hypertension [8].

The role of oxidative stress (OS) in the development of obesity and its complications has already been established [9-12]. Recent studies emphasize the critical role of OS in the development of tumors [13-16]. In this process, overproduction of reactive oxygen species (ROS) and nitrogen (RNS) with a simultaneous reduction in enzymatic and nonenzymatic antioxidant protection was observed [17, 18]. Redox imbalance may lead to initiation, progression, and growth of tumor cells by activating redox-responsive signaling cascades [19]. It is well known that ROS induce peroxidation of lipids and proteins, leading to highly cytotoxic oxidation products for the cell [20]. Protein oxidation products accumulate in cells, inhibit proteasomes' activity, and cause further structural and functional damage to cell organelles [21]. Moreover, oxidative stress can damage DNA, contribute to cell death through necrosis, and inhibit apoptosis [22]. Although the antioxidant/oxidative homeostasis is disrupted in cancers, antioxidant systems protect cells from OS's damaging effects and repair some oxidative damage to biomolecules. Unfortunately, nothing is known about the effectiveness of the antioxidant barrier in patients with adrenal tumors. It is unclear whether disorders in redox mechanisms are associated with adrenal masses. Therefore, our study is aimed at assessing the enzymatic and nonenzymatic antioxidant barrier, glutathione metabolism, and oxidative damage to lipids, proteins, and DNA/RNA in the plasma, serum, and urine of patients with adrenal mass compared to the healthy controls. We are also the first to compare redox homeostasis between adrenal incidentalomas, pheochromocytomas, and Cushing/Conn adenoma.

\section{Materials and Methods}

The study was designed, conducted, and reported according to the guidelines for Good Clinical Practice and the Declaration of Helsinki and approved by the Bioethics Committee of the Medical University of Bialystok (permission numbers: RI-002/66/2015, APK.002.341.2020). All patients participating in the study gave their informed consent.

The study included 70 patients (37 women and 33 men aged from 50 to 65 years) with adrenal masses diameter $>1$ $\mathrm{cm}$ and $<8 \mathrm{~cm}$, who underwent elective endoscopic adrenalectomy using either lateral transperitoneal approach or pos- terior retroperitoneal approach. Patients were diagnosed at internal medicine departments with an endocrinology profile and treated surgically at the 1st Department of General and Endocrine Surgery at the University Hospital in Bialystok, Poland. The study group was divided into three subgroups: patients with incidentaloma $(n=30)$, pheochromocytoma $(n=20)$, and adenoma $(n=20)$. In the adenoma subgroup, 11 patients were diagnosed with Cushings', and 9 patients were diagnosed with Conns' syndrome. Patients with suspected phaeochromocytoma were treated with doxazosin-a selective alpha-1-adrenergic receptor blocker, for 10-14 days before surgery to avoid intraoperative hypertensive crisis. Patients with Conn's syndrome were supplemented with potassium or took spironolactone-an aldosterone receptor blocker in the preoperative period.

The control group consisted of 60 healthy individuals (31 women and 29 men aged from 50 to 65 years) who underwent a dental follow-up visit at the Specialist Dental Clinic at the Medical University of Bialystok. Only people with blood counts and biochemical blood test $(\mathrm{Na}+, \mathrm{K}+$, INR, AST, ALT and creatinine) values within the reference range were qualified to the control group.

The exclusion criteria for both study and control groups were acute inflammation, neoplastic diseases, metabolic diseases (insulin resistance, type 1 and type 2 diabetes, osteoporosis, gout, and mucopolysaccharidosis), autoimmune diseases (including ulcerative colitis, Hashimoto's disease, and Crohn's disease), cardiovascular diseases (other than hypertension in the study group), diseases of the respiratory, digestive and genitourinary systems, infectious diseases (HIV/AIDS, hepatitis A, B, and C), smoking, and alcohol abuse, as well as pregnancy in women.

Three months prior to collecting the material for the study, the patients from the study and control groups declared not taking nonsteroidal anti-inflammatory drugs, glucocorticosteroids, antibiotics, and vitamins and antioxidant supplements. The clinical characteristics of the study and control groups are demonstrated in Table 1.

2.1. Blood and Urine Collection. All samples were collected in a fasting state from patients with adrenal mass and healthy individuals who did not perform intense physical exercise twenty-four hours prior to blood sampling. Blood was collected into serum and EDTA tubes (S-Monovette SARSTEDT) and centrifuged at $4000 \mathrm{rpm}$ for 10 minutes at $4^{\circ} \mathrm{C}$. Urine for testing was collected in a sterile disposable container, immediately after bedtime, from the first morning portion of urine from the middle stream. The urine sample was centrifuged for 5 minutes at $1500 \mathrm{pm}$. The supernatant was protected against oxidation $(10 \mu \mathrm{l}$ of $0.5 \mathrm{M} \mathrm{BHT} / 1 \mathrm{ml}$ of serum/plasma and urine) and stored at $-80^{\circ} \mathrm{C}$ until the final analysis $[23,24]$. The samples were stored at $-80^{\circ} \mathrm{C}$ for no longer than six months.

2.2. Laboratory Measurements. Serum $\mathrm{Na}+, \mathrm{K}+$, full blood count, glucose, aldosterone, and serum cortisol before 10 a.m., as well as urine methanephrine and normethanephrine, were quantified by using an Abbott analyzer (Abbott Diagnostics, Wiesbaden, Germany). 
TABLE 1: Clinical and laboratory characteristics of the controls, incidentaloma, pheochromocytoma, and Cushing's/Conn's adenoma patients. Results are presented as median with $25 \%$ and $75 \%$ percentiles. ${ }^{*} p<0.05,{ }^{* *} p<0.01,{ }^{* * *} p<0.001$, and ${ }^{* * * *} p<0.0001$ indicate significant differences from the controls; $\wedge p<0.05, \wedge \wedge \wedge \wedge p<0.0001$ indicates significant differences from the pheochromocytoma group; $\sim p<0.05$ indicates significant differences from Cushing's/Conn's adenoma group. BMI: body mass index; HGB: hemoglobin; PLT: platelet count; RBC: red blood cell count; WBC: white blood cell count.

\begin{tabular}{|c|c|c|c|c|c|}
\hline & Controls $(n=60)$ & $\begin{array}{l}\text { Incidentaloma } \\
\quad(n=30)\end{array}$ & $\begin{array}{l}\text { Pheochromocytoma } \\
\qquad(n=20)\end{array}$ & $\begin{array}{l}\text { Cushig's/Conn's } \\
\text { adenoma }(n=20)\end{array}$ & ANOVA \\
\hline Age & $59(50-65)$ & $61(54-65)$ & $56(50-65)$ & $59(53-65)$ & $p=0.6506$ \\
\hline BMI $\left(\mathrm{kg} / \mathrm{m}^{2}\right)$ & $23.04(22.6-23.82)$ & $29.62^{* * * *}(26.13-34.98)$ & $26.75^{*}(22.58-31.97)$ & $30.57^{* * * *}(27.1-32.5)$ & $p<0.0001$ \\
\hline Glucose (mg/dl) & $76(72-82.25)$ & $101^{* * *}(89.5-113.5)$ & $84.5^{*}(79.25-104.3)$ & $97.5^{* * *}(82.5-110)$ & $p<0.0001$ \\
\hline $\mathrm{Na}^{+}(\mathrm{mmol} / \mathrm{l})$ & $139(137-140)$ & $140(138-141)$ & $139.5(137-141)$ & $138(136-141)$ & $p=0.1764$ \\
\hline $\mathrm{K}^{+}(\mathrm{mmol} / \mathrm{l})$ & $4.39(4.15-4.66)$ & $4.51(4.29-4.81)$ & $4.28(4.06-4.69)$ & $4.32(3.78-4.65)$ & $p=0.1333$ \\
\hline $\mathrm{WBC}\left(10^{3} / \mu \mathrm{l}\right)$ & $7.5(6.8-8.3)$ & $7.04(5.265-8.8)$ & $7.51(6.428-8.743)$ & $7.27(6.038-9.17)$ & $p=0.7462$ \\
\hline $\operatorname{RBC}\left(10^{6} / \mu \mathrm{l}\right)$ & $4.6(4.5-4.9)$ & $4.74(4.35-4.98)$ & $4.51(4.135-4.808)$ & $4.625(4.385-4.81)$ & $p=0.3823$ \\
\hline HGB (g/dl) & $13.8(13.4-14.1)$ & $14.2(13.5-14.7)$ & $14.1(12.7-14.9)$ & $14.1(13.3-14.5)$ & $p=0.2541$ \\
\hline $\operatorname{PLT}\left(10^{3} / \mu \mathrm{l}\right)$ & $289(275-300)$ & $225^{* * * *}(183.5-270.5)$ & $264.5(215-285.3)$ & $195^{* * * * \wedge}(165-237)$ & $p<0.0001$ \\
\hline $\begin{array}{l}\text { Serum cortisol before } \\
10 \text { a.m. }(\mu \mathrm{g} / \mathrm{dl})\end{array}$ & $11(9.2-16)$ & $15(11-19)$ & $15(11-20)$ & $12(10-20)$ & $p=0.0506$ \\
\hline $\begin{array}{l}\text { Urine methanephrine } \\
(\mu \mathrm{g} / 24 \mathrm{~h})\end{array}$ & $118(87-208)$ & $98^{\wedge} \wedge \wedge \wedge(78-176)$ & $592^{* * * *}(425-862)$ & $122.5^{\wedge \wedge \wedge \wedge}(94-223)$ & $p<0.0001$ \\
\hline $\begin{array}{l}\text { Urine normethanephrine } \\
(\mu \mathrm{g} / 24 \mathrm{~h})\end{array}$ & $234(173-308)$ & $233 \wedge \wedge \wedge \wedge \sim(174-331)$ & $655^{* * *}(553-934)$ & $394^{* * \wedge}(271-435)$ & $p<0.0001$ \\
\hline Aldosterone (ng/dl) & $12.3(8.63-20.18)$ & $12.08^{\sim}(6.8-19.56)$ & $16.3(10.82-21.88)$ & $18.56^{*}(11.56-35.8)$ & $p=0.0195$ \\
\hline Size of the tumor $(\mathrm{cm})$ & & $4.2(2.65-5.5)$ & $3.8(3.5-4.8)$ & $3.45(2.025-4.95)$ & $p=0.4155$ \\
\hline
\end{tabular}

2.3. Redox Assays. All reagents used for the redox assays were from Sigma-Aldrich (Nümbrecht, Germany/Saint Louis, MO, USA). Antioxidant enzymes were determined in serum. The nonenzymatic antioxidants, redox status, and oxidation products were evaluated in the plasma. The 96-well microplate reader BioTek Synergy H1 (Winooski, VT, USA) was used to measure absorbance/fluorescence. All determinations were conducted in duplicate samples and standardized to 1 $\mathrm{mg}$ of the total protein. The total protein content was assayed colorimetrically by the bicinchoninic acid assay with bovine serum albumin as a standard (Thermo Scientific PIERCE BCA Protein Assay Kit, Rockford, IL, USA).

2.4. Antioxidant Barrier. The activity of serum $\mathrm{Cu}-\mathrm{Zn}$ superoxide dismutase (SOD, EC 1.15.1.1) was evaluated spectrophotometrically at $480 \mathrm{~nm}$ by measuring the inhibition rate of adrenaline oxidation [25]. One unit of SOD activity was qualified as the amount of enzyme inhibiting adrenaline oxidation by $50 \%$. The activity of serum catalase (CAT, EC 1.11.1.6) was determined by measuring at 240 $\mathrm{nm}$ spectrophotometrically hydrogen peroxide (H2O2) decomposition [26]. One unit of CAT activity was qualified as the quantity of the enzyme catalyzing decomposition of $1 \mathrm{mM}$ of $\mathrm{H}_{2} \mathrm{O}_{2}$ per $1 \mathrm{~min}$. The activity of serum glutathione peroxidase (GSH-Px, EC 1.11.1.9) was evaluated spectrophotometrically at $340 \mathrm{~nm}$ by measuring the reduction of organic peroxides by GSH-Px in the presence of reduced nicotinamide adenine dinucleotide phosphate (NADPH) [27]. The activity of serum glutathione reductase (GR, EC 1.8.1.7) was assessed spectrophotometrically based on the decrease in NADPH absorbance at $340 \mathrm{~nm}$ [28]. One unit of GR activity was defined as the quantity of enzyme catalyzing the oxidation of $1 \mu \mathrm{M}$ NADPH per $1 \mathrm{~min}$.

The concentration of plasma uric acid (UA) was evaluated spectrophotometrically using the commercial kit (QuantiChromTM Uric Acid DIUA-250; BioAssay Systems, Harward, CA, USA), according to the manufacturer's instructions. The absorbance was measured at $630 \mathrm{~nm}$. The concentration of plasma glutathione was determined colorimetrically at $412 \mathrm{~nm}$ based on the enzymatic reaction NADPH, 5,5' dithiobis-(2-nitrobenzoic acid) (DTNB) and GR [29]. The reduced glutathione (GSH) concentration was counted from the difference between the concentration of total glutathione and oxidized glutathione (GSSG). Redox status was calculated according to the formula $=[\mathrm{GSH}]^{2} /[\mathrm{GSSG}][30]$.

2.5. Oxidative Stress Products. The concentration of malondialdehyde (MDA) was assessed colorimetrically with the TBARS method using thiobarbituric acid (TBA). 1,1,3,3Tetraethoxypropane was used as the standard, and determination was performed at a $535 \mathrm{~nm}$ wavelength [31]. The concentration of lipid hydroperoxides (LOOH) was measured spectrophotometrically with the FOX-2 test using the reaction of iron (3+) ions with xylenol orange (XO) $[32,33]$. The absorbance of the Fe-XO complex was measured at a $560 \mathrm{~nm}$ wavelength. The content of plasma advanced glycation end products (AGE) was determined spectrofluorimetrically at $350 / 440 \mathrm{~nm}$ by measuring AGEspecific fluorescence [34]. The concentration of plasma advanced oxidation protein products (AOPP) was evaluated 
spectrophotometrically by measuring the plasma's iodide ion oxidizing capacity at $340 \mathrm{~nm}$ [34]. Immediately before the assay of AGE and AOPP, plasma was diluted $(1: 5, \mathrm{v}: \mathrm{v})$ in $0.02 \mathrm{M}$ PBS, pH7.4 [35]. The concentration of plasma DNA/RNA oxidative damage was assayed according to the manufacturer's instructions, using commercial high sensitivity ELISA kits (DNA/RNA oxidative damage ELISA Kit, Cayman Chemicals, Ann Arbor, MI, USA, respectively). The test detects all three oxidized guanine species; 8-hydroxy-2' deoxyguanosine from DNA, 8-hydroxyguanosine from RNA, and 8-hydroxyguanine from either DNA or RNA. The assay has a range from 10.3 to $3,000 \mathrm{pg} / \mathrm{ml}$ and a sensitivity of approximately $30 \mathrm{pg} / \mathrm{ml}$.

2.6. Statistical Analysis. The statistical significance level was set at $p<0.05$. The normality of the distribution was assessed using the Shapiro-Wilk test, while homogeneity of variance used the Levene test. For comparison of quantitative variables, the Kruskal-Wallis ANOVA test and Dunn's posthoc test were used. Multiplicity adjusted $p$ value was also calculated. The relationship between the assessed redox biomarkers was evaluated using the Spearman rank correlation. Statistical analysis was performed using GraphPad Prism 8.3.0 for macOS (GraphPad Software, Inc. La Jolla, USA).

The number of subjects was determined based on our previous experiment, assuming that the test's power would be equal to 0.9 (online ClinCalc sample size calculator).

\section{Results}

Table 1 shows a comparison of the clinical and routine laboratory characteristics of the controls, incidentaloma, pheochromocytoma, and Cushing's/Conn's adenoma patients. We found significantly higher BMI and serum glucose values in patients with adrenal masses compared to the healthy controls. Urinary metanephrine and normetanephrine were greater in the pheochromocytoma group than any other group. In contrast, aldosterone was increased in Cushing's/Conn's adenoma group as compared to the controls. The PLT content was lower in patients with incidentaloma and Cushing's/Conn's adenoma than in the controls.

3.1. Superoxide Dismutase (SOD). The activity of serum SOD was significantly decreased in all studied groups: incidentaloma $(-43 \%, p<0.0001)$, pheochromocytoma $(-47 \%, p<$ $0.0001)$, and Cushing's/Conn's adenoma (-37\%, $p<0.0001)$ as compared to the healthy controls (Figure 1(a)). urine SOD activity was markedly lower in pheochromocytoma $(-62 \%, p=0.0052)$ and Cushing's/Conn's adenoma (-63\%, $p<0.0001)$ groups than the controls. Moreover, incidentaloma urine SOD activity was higher than pheochromocytoma $(+193 \%, p=0.0002)$ and Cushing's/Conn's adenoma $(+197 \%, p<0.0001)$ groups (Figure 1(b)). Additionally, the serum/urine index of SOD activity in incidentaloma $(-50 \%, \mathrm{p}<0.0001)$ was diminished in comparison with the controls. Interestingly, the serum/urine index of SOD activity in incidentaloma was lower than pheochromocytoma $(-41 \%, p=0.0064)$ and Cushing's/Conn's adenoma (-64\%, $p<0.0001$ ) groups (Figure 1(c)).
3.2. Catalase (CAT). We found lower serum activity of CAT only in patients with pheochromocytoma $(-58 \%, p<0.001)$ in comparison with the controls (Figure $1(\mathrm{~d})$ ). The activity of urine CAT was significantly increased in all studied groups: incidentaloma $(+31 \%, p<0.0001)$, pheochromocytoma ( $+34 \%, p<0.0001)$, and Cushing's/Conn's adenoma (+26\%, $p=0.0016)$ as compared to the healthy controls (Figure 1(e)), whereas serum/urine index of CAT activity was decreased: incidentaloma $(-50 \%, p<0.0001)$, pheochromocytoma $(-73 \%, p<0.0001)$, and Cushing's/Conn's adenoma $(-39 \%, p=0.0092)$ (Figure $1(\mathrm{f}))$.

3.3. Glutathione Peroxidase (GSH-Px). We observed greater serum and urine activity of GSH-Px in patients witch adrenal masses: incidentaloma (+90\%, $p<0.0001 ;+92 \%, p<0.0001)$, pheochromocytoma $(91+\%, p<0.0001 ;+198 \%, p<0.0001)$, and Cushing's/Conn's adenoma (+96\%, $p<0.0001 ;+192 \%$, $p<0.0001$ ) as compared to the controls (Figures $1(\mathrm{~g})$ and $1(\mathrm{~h})$ ), while serum/urine index of GSH-Px activity did not differ between studied groups and the controls (Figure 1(i)).

3.4. Glutathione Reductase (GR). There were no statistically significant differences in the activity of serum and urine GR and serum/urine index of GR activity in studied groups (incidentaloma, pheochromocytoma, and Cushing's/Conn's adenoma) compared with the controls (Figures 1(j), (k), and (l)).

3.5. Total Glutathione. Total glutathione concentration in plasma did not differ between studied groups (Figure 2(a)). We found lower total glutathione concentration only in urine of pheochromocytoma $(-12 \%, p=0.0011)$ patients than the controls (Figure 2(b)). Moreover, plasma/urine index of GR concentration in Cushing's/Conn's adenoma patients was diminished $(-31 \%, p=0.0299)$ in comparison with the pheochromocytoma group (Figure 2(c)).

3.6. Reduced Glutathione (GSH). The plasma concentration of GSH, as well as plasma/urine index of GSH concentration, were decreased of all studied groups: incidentaloma $(-53 \%$, $p<0.0001 ;-44 \%, p<0.0001)$, pheochromocytoma $(-52 \%$, $p<0.0001 ;-33 \%, p=0.0059)$, and Cushing's/Conn's adenoma $(-27 \%, p=0.0001 ;-3 \%, p=0.0008)$ as compared to the healthy controls (Figures 2(d) and 2(f)), while urine concentration of GSH was lower only in pheochromocytoma patients $(-29 \%, p<0.0001)$ (Figure 2(e)).

3.7. Glutathione Disulfide (GSSG). The plasma concentration of GSSG was significantly higher only in patients with pheochromocytoma ( $+95 \%, p=0.0079)$ compared to the controls. Additionally, in Cushing's/Conn's adenoma group, GSSG plasma concentration was lower $(-46 \%, p=0.0299)$ than the pheochromocytoma group (Figure $2(\mathrm{~g})$ ). We did not find any differences in urine concentration of GSSG (Figure 2(h)). The plasma/urine index of GSSG concentration was greater in pheochromocytoma $(+68 \%, p=0.0071)$ than the controls (Figure 2(i)).

3.8. Redox Status. We observed that plasma redox status was significantly diminished in all studied groups: incidentaloma $(-78 \%, p<0.0001)$, pheochromocytoma $(-85 \%, p<0.0001)$, 


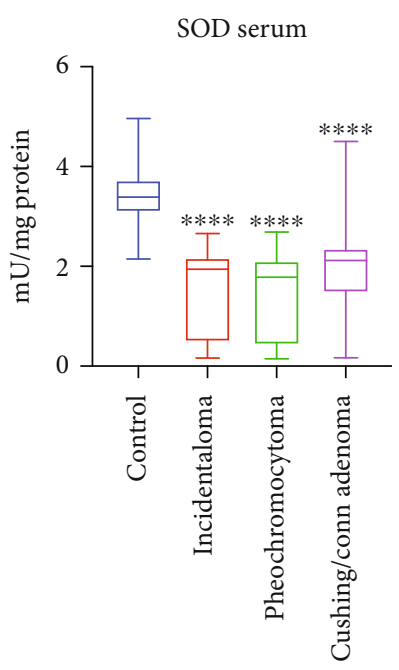

(a)

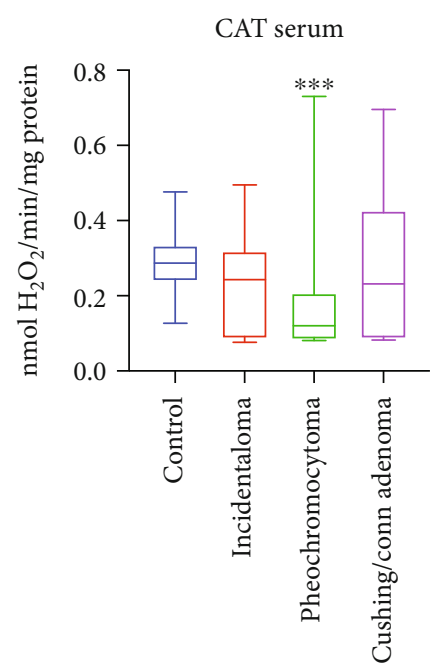

(d)

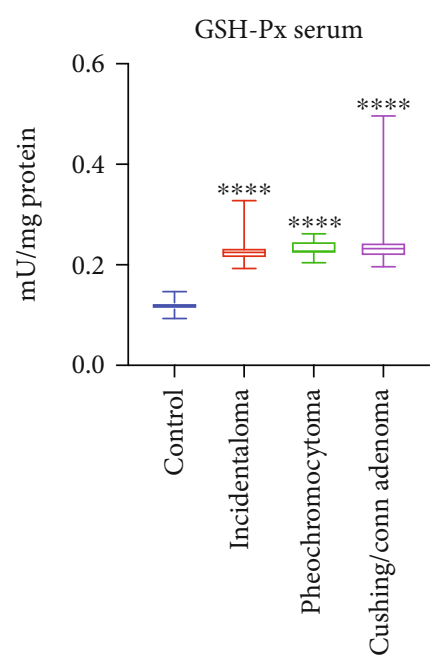

(g)

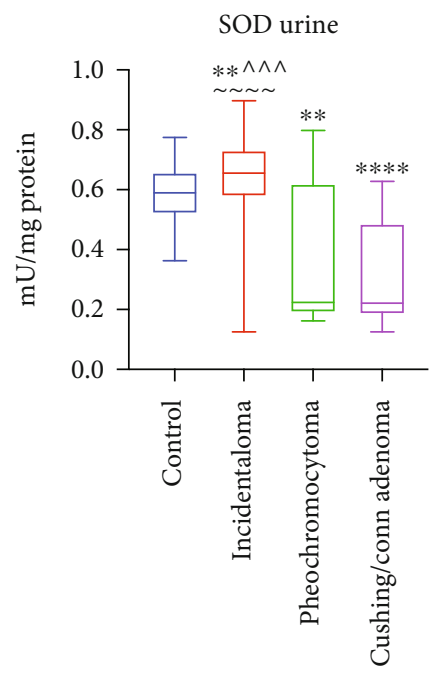

(b)

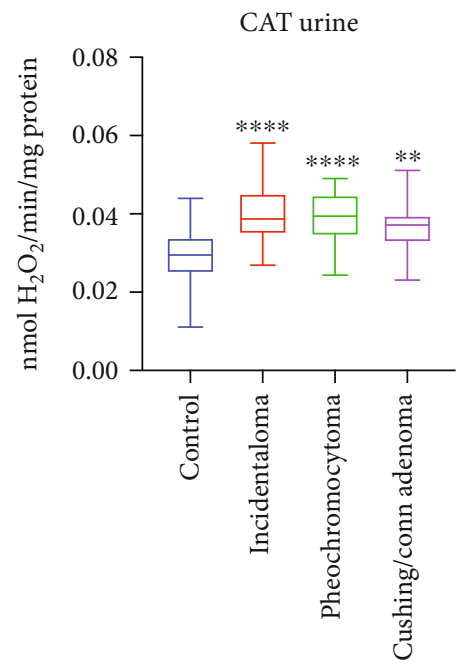

(e)

GSH-Px urine

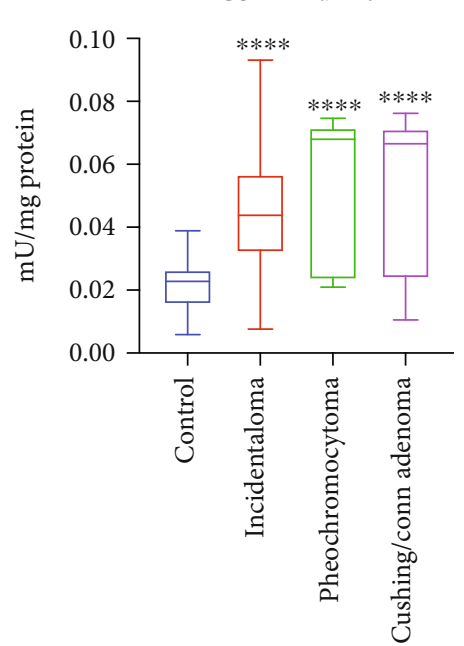

(h)

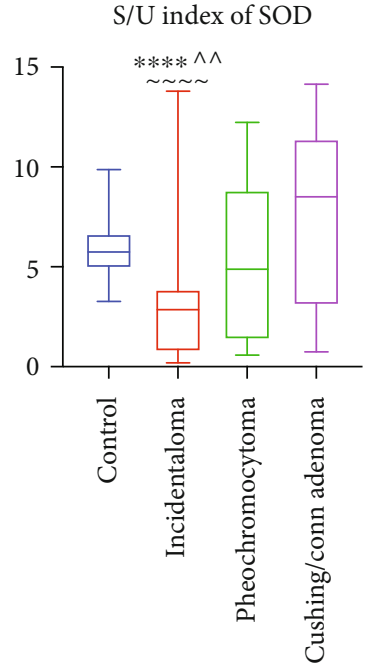

(c)

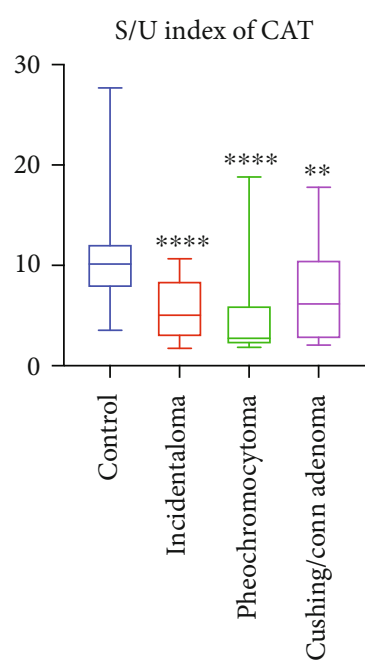

(f)

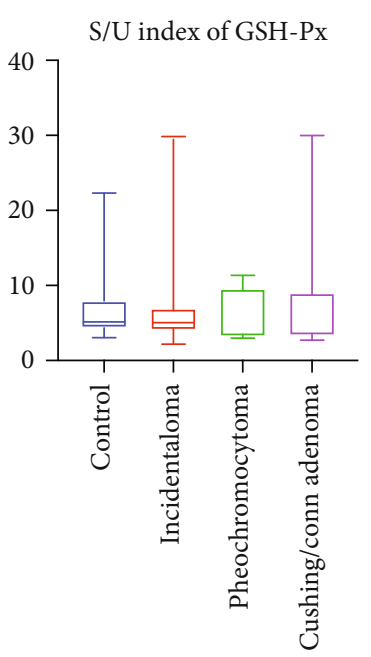

(i)

Figure 1: Continued. 


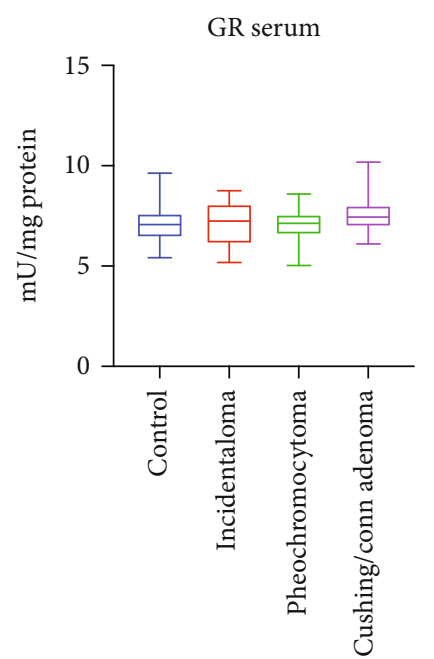

(j)

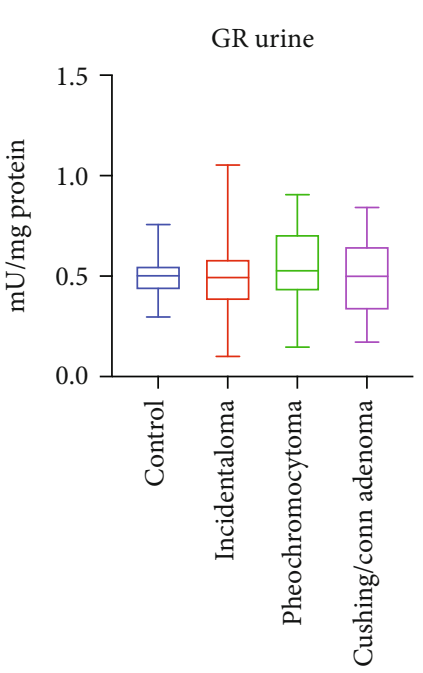

$(\mathrm{k})$

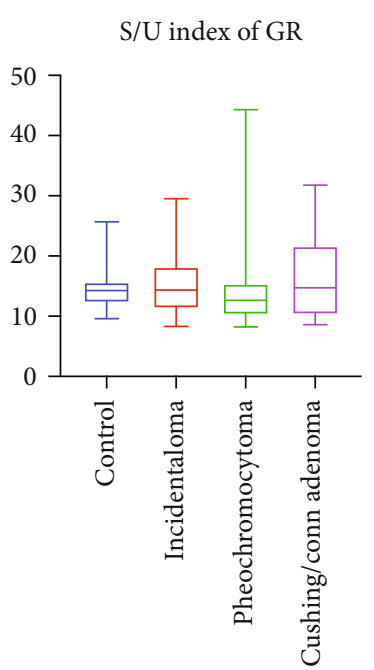

(1)

Figure 1: The activity of serum and urine enzymatic antioxidants ( $a, b, d, e, g, h, j, k)$, as well as serum/urine index of enzymatic antioxidants activity ( $c, f, i, l)$ of the controls, incidentaloma, pheochromocytoma, and Cushing's/Conn's adenoma patients. Results are presented as median with minimum and maximum. ${ }^{* *} p<0.01,{ }^{* * *} p<0.001$, and ${ }^{* * * *} p<0.0001$ indicate significant differences from the controls; $\wedge \wedge p<0.01$ and $\wedge \wedge \wedge p<0.001$ indicate significant differences from the pheochromocytoma group; SOD: superoxide dismutase; CAT: catalase; GSH-Px: glutathione peroxidase; GR: glutathione reductase (GR).

and Cushing's/Conn's adenoma $(-68 \%, p=0.0111)$ as compared to the healthy controls. Interestingly, the plasma redox status was the most decreased in the pheochromocytoma group (Figure $2(\mathrm{j}))$. In urine, redox status was decreased only in pheochromocytoma $(-35 \%, p=0.0012)$ (Figure $2(\mathrm{k})$ ). The plasma/urine index of redox status was lower in all patients with adrenal masses: incidentaloma $(-74 \%, p<0.0001)$, pheochromocytoma $(-56 \%, p=0.0124)$, and Cushing's/Conn's adenoma $(-65 \%, p=0.0283)$ than in the controls (Figure 2(l)).

3.9. Uric Acid (UA). The plasma concentration of UA was significantly diminished in incidentaloma $(-15 \%, p=0.0001)$ and pheochromocytoma $(-23 \%, p=0.0025)$ groups in comparison with the controls (Figure 3(a)). We observed significantly lower urine concentration of UA in all groups of patients with adrenal masses: incidentaloma $(-20 \%, p=$ $0.0005)$, pheochromocytoma $(-25 \%, p<0.0001)$, and Cushing's/Conn's adenoma $(-12 \%, p=0.002)$ (Figure 3(b)). There were no differences in the plasma/urine index of UA concentration between studied groups (Figure 3(c)).

3.10. Advanced Glycation End Products (AGE). The AGE plasma and urine content were greater in patients with adrenal masses incidentaloma $(+179 \%, p<0.0001 ;+79 \%, p<$ 0.0001 ), pheochromocytoma $(+180 \%, p<0.0001 ;+157 \%$, $p<0.0001)$, and Cushing's/Conn's adenoma $(+165 \%, p<$ $0.0001 ;+90 \%, p<0.0001)$ in comparison with the controls (Figures 4(a) and 4(b)), while the plasma/urine index of the AGE content was higher in incidentaloma $(+46 \%, p=0.0196)$ and Cushing's/Conn's adenoma $(+67 \%, p=0.0463)$ than the controls (Figure 4(c)).

3.11. Advanced Oxidation Protein Products (AOPP). We found a significantly higher plasma and urine concentration of AOPP in all studied groups: incidentaloma $(+111 \%, p<$
$0.0001 ;+51 \%, \quad p<0.0001)$, pheochromocytoma $(+217 \%$, $p<0.0001 ;+77 \%, p<0.0001)$, and Cushing's/Conn's adenoma $(+61 \%, p=0.0013 ;+46 \%, p=0.0006)$ as compared to the controls. Additionally, patients with Cushing's/Conn's adenoma had lower plasma concentration of AOPP (-49\%, $p=0.0139)$ than pheochromocytoma ones (Figures 4(d) and 4(e)). The plasma/urine index of the AOPP content did not differ between studied groups (Figure 4(f)).

3.12. Lipid Hydroperoxides ( $\mathrm{LOOH}$ ). The patients with adrenal masses had a markedly higher concentration of plasma LOOH than the controls: incidentaloma $(+168 \%, p<0.0001)$, pheochromocytoma $(+249 \%, p<0.0001)$, and Cushing's/ Conn's adenoma $(+227 \%, p<0.0001)$ (Figure 5(a)), whereas in urine, the concentration of $\mathrm{LOOH}$ was greater in incidentaloma $(+184 \%, p=0.0003)$ and pheochromocytoma $(+223 \%, p<0.0001)$ groups. Interestingly, the urine concentration of LOOH in Cushing's/Conn's adenoma patients (-61\%, $p=0.0075)$ was lower than in the pheochromocytoma group (Figure 5(b)). Further on, the plasma/urine index of $\mathrm{LOOH}$ concentration in Cushing's/Conn's adenoma group was increased in comparison with the controls $(+73 \%, p=0.0135)$ and pheochromocytoma $(+116 \%, p=0.0076)$ (Figure 5(c)).

3.13. Malondialdehyde (MDA). The plasma concentration of MDA was increased in patients with adrenal masses as compared to the controls: incidentaloma $(+52 \%, p<0.0001)$, pheochromocytoma $(+114 \%, p<0.0001)$, and Cushing's/ Conn's adenoma $(+42 \%, p=0.0001)$. Moreover, we noticed that the MDA plasma concentration in patients with incidentaloma $(-29 \%, p=0.0239)$ and Cushing's/Conn's adenoma $(-33 \%, p=0.0341)$ was lower than in the pheochromocytoma group (Figure 5(d)). The urine concentration of MDA was markedly higher in pheochromocytoma $(+35 \%, p=0.0002)$ and Cushing's/Conn's adenoma $(+25 \%, p=0.0008)$ groups 


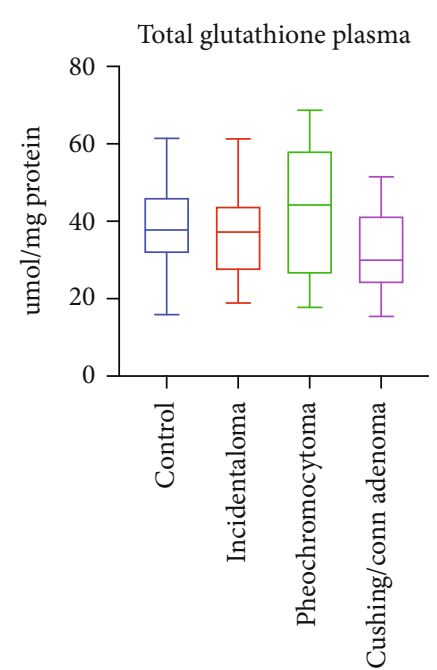

(a)

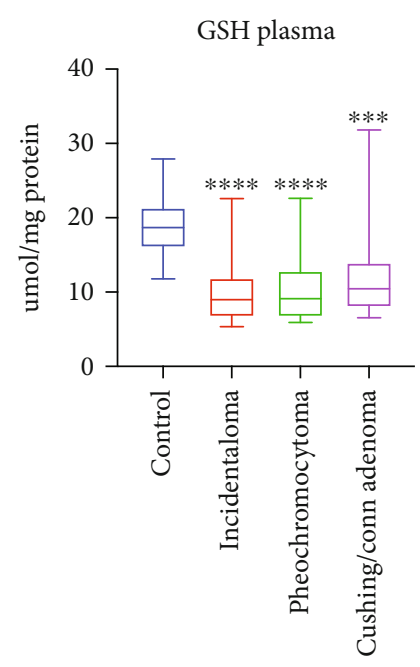

(d)

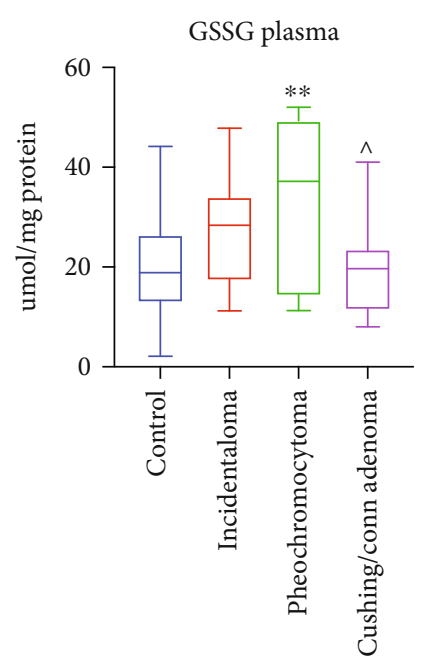

(g)

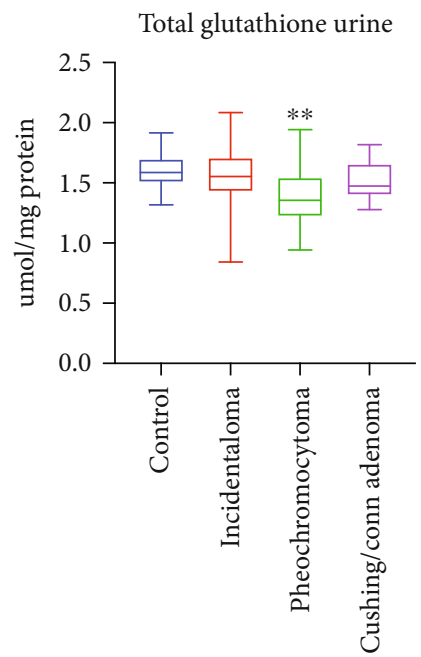

(b)

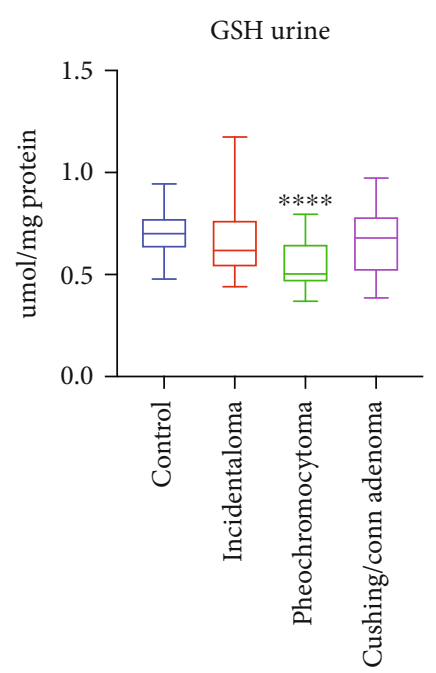

(e)

GSSG urine

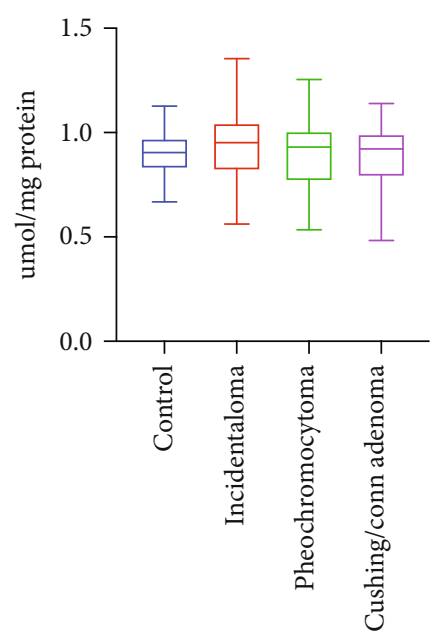

(h)

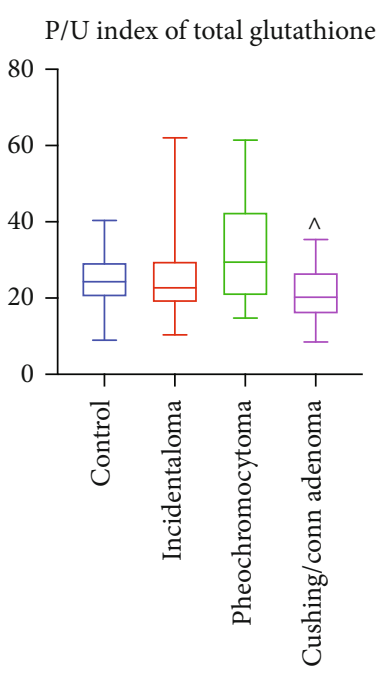

(c)

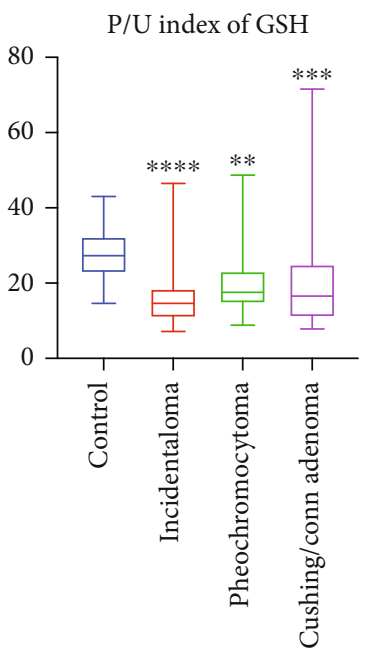

(f)

$\mathrm{P} / \mathrm{U}$ index of GSSG

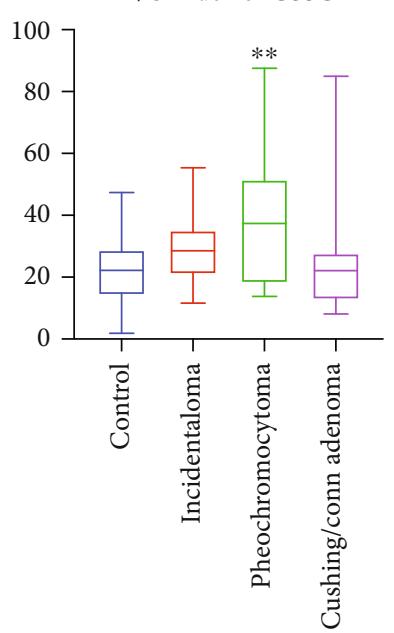

(i)

Figure 2: Continued. 


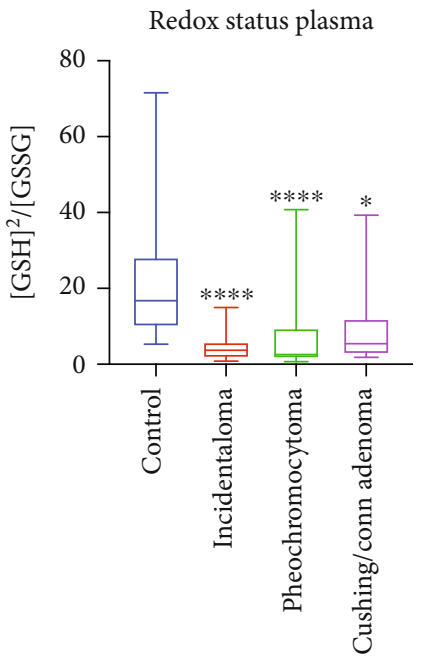

(j)

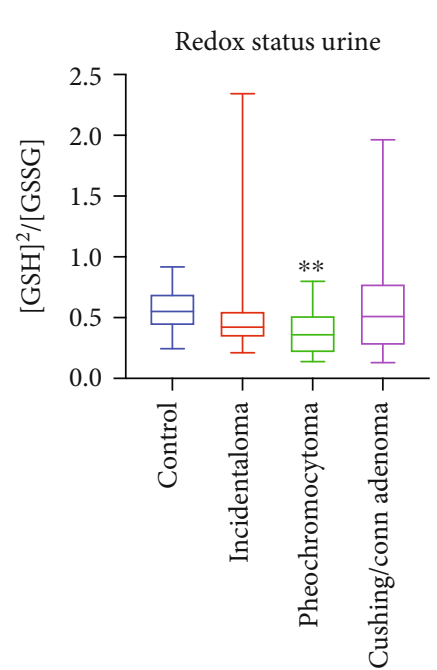

(k)

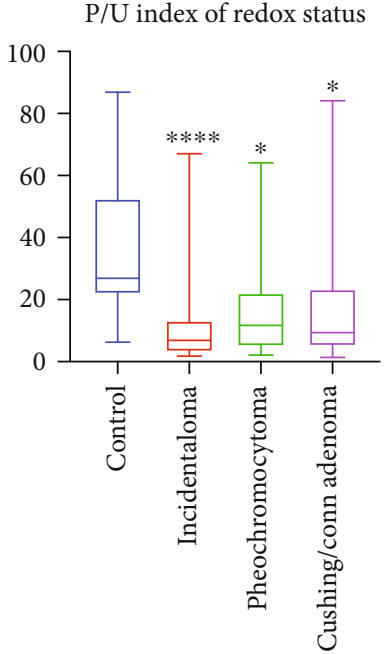

(1)

Figure 2: Plasma and urine concentration, as well as plasma/urine index of total glutathione (a-c), reduced glutathione (GSH) (d, e, f), glutathione disulfide (GSSG) (g)-(i), and redox status (j)-(l) of the controls, incidentaloma, pheochromocytoma, and Cushing's/Conn's adenoma patients. Results are presented as median with minimum and maximum. ${ }^{*} p<0.05,{ }^{* *} p<0.01,{ }^{* * *} p<0.001$, and ${ }^{* * * *} p<0.0001$ indicate significant differences from the controls; $\wedge p<0.05$ indicates significant differences from the pheochromocytoma group.

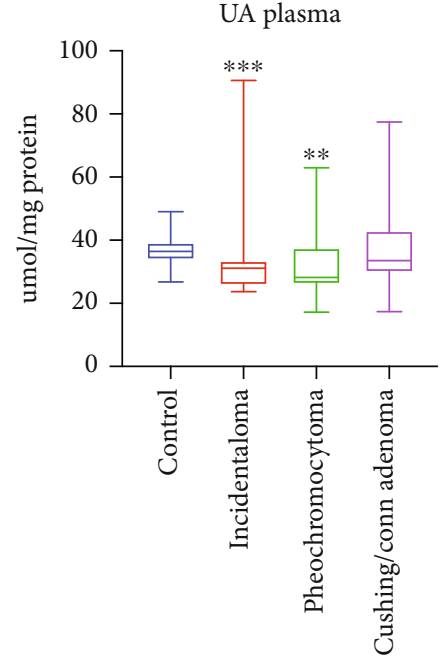

(a)

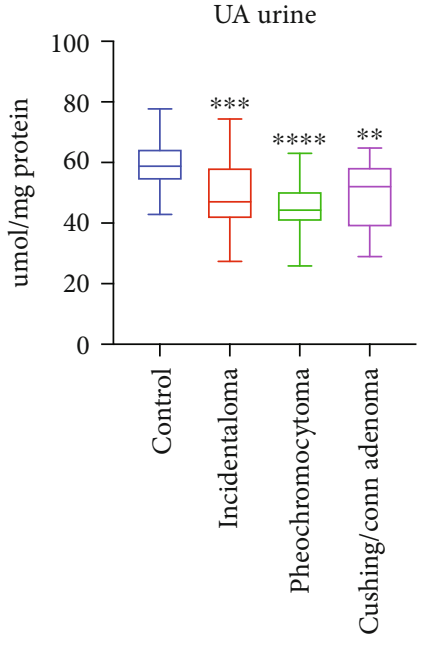

(b)

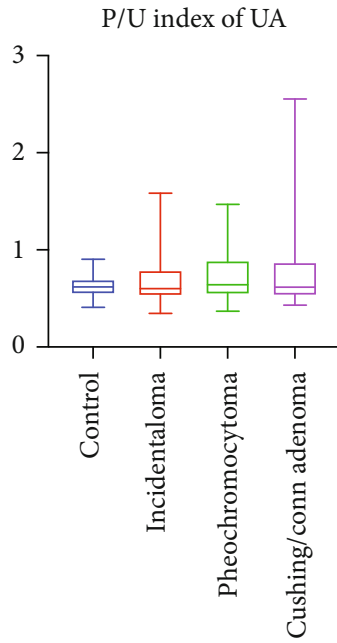

(c)

FIGURE 3: Uric acid (UA) concentration in plasma and urine $(a, b)$, as well as plasma/urine index of UA concentration (c) of the controls, incidentaloma, pheochromocytoma, and Cushing's/Conn's adenoma patients. Results are presented as median with minimum and maximum. ${ }^{* *} p<0.01,{ }^{* * *} p<0.001$, and ${ }^{* * * *} p<0.0001$ indicate significant differences from the controls.

in comparison with the controls (Figure 5(e)). The plas$\mathrm{ma}$ /urine index of MDA concentration was greater in incidentaloma (+39\%, $p=0.0049)$ and pheochromocytoma $(+60 \%, p=0.0017)$ than the controls (Figure 5(f)).

3.14. DNA/RNA Oxidation Products. The DNA/RNA oxidation product content was significantly increased in groups: incidentaloma $(+33 \%, p=0.0005)$ and pheochromocytoma $(+99 \%, p<0.0001)$ groups as compared to the controls. Moreover, the DNA/RNA oxidation product content was lower in the incidentaloma $(-33 \%, p=0.0063)$ and Cushing's/Conn's adenoma groups $(-40 \%, p=0.0004)$ than the patients with pheochromocytoma (Figure 6(a)). In urine, patients with incidentaloma $(+61 \%, p=0.0001)$ and pheochromocytoma $(+130 \%, p<0.0001)$ had greater contents of DNA/RNA oxidation products than the controls (Figure 6(b)). We did not find any significant differences in the plasma/urine index of DNA/RNA oxidation products between any of the groups (Figure 6(c)).

We checked the diagnostic usefulness of the assessed redox biomarkers of adrenal masses. The results of ROC analysis are presented in Table 2. We identified a potential diagnostic utility for pheochromocytoma patients for the plasma MDA (sensitivity 95\%; specificity 96.67\%) and 


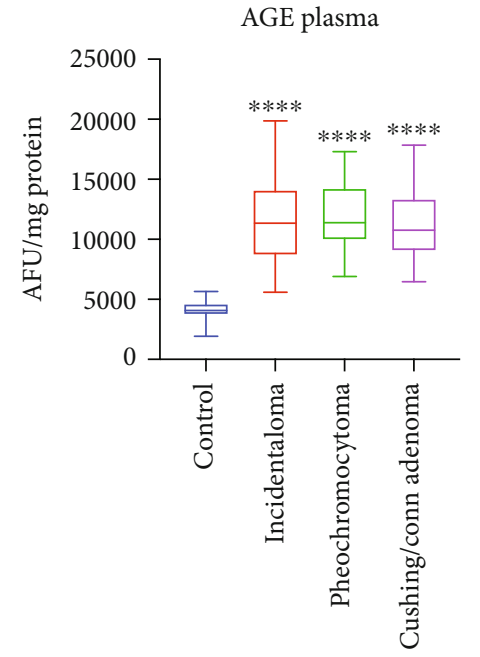

(a)

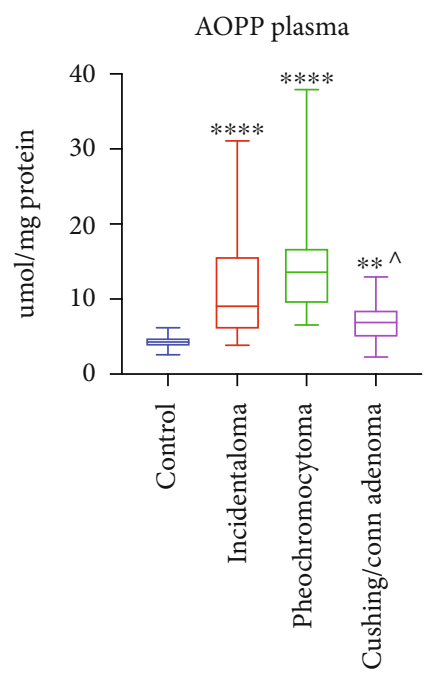

(d)

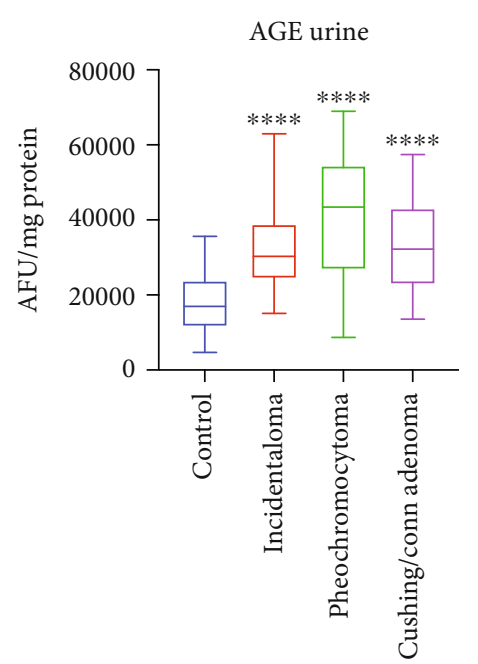

(b)

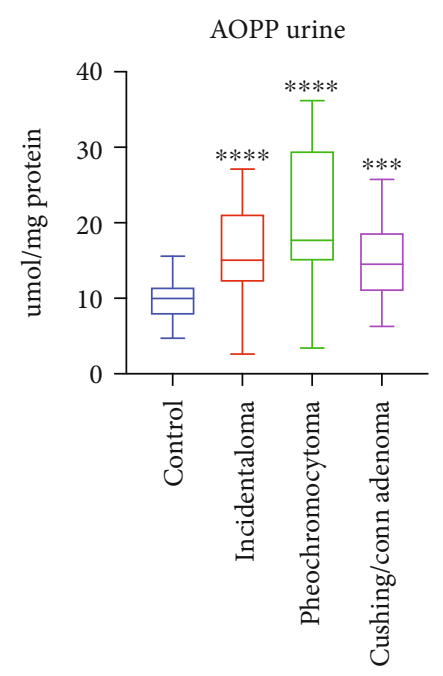

(e)

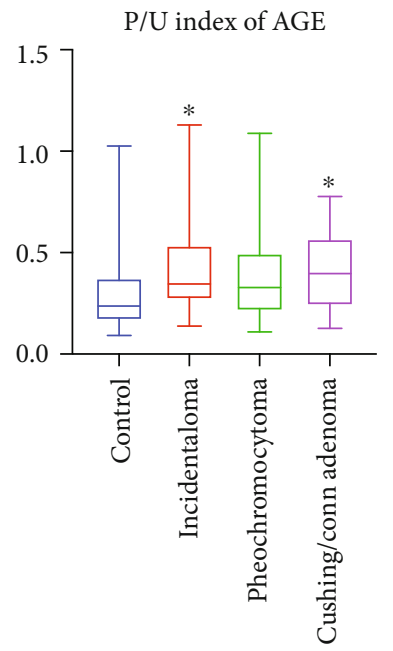

(c)

$\mathrm{P} / \mathrm{U}$ index of AOPP

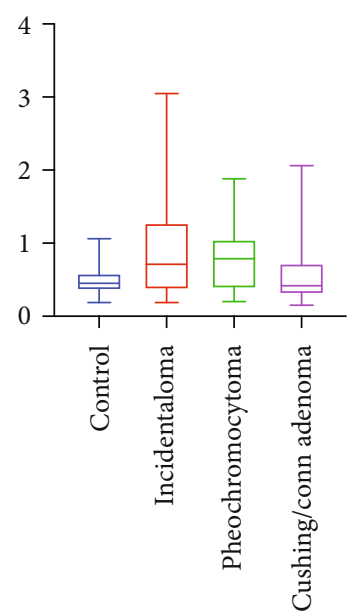

(f)

FIGURE 4: Plasma and urine content of advanced glycation end products (AGE) (a, b) and advanced oxidation protein products (AOPP) (d, e), as well as plasma/urine index of the AGE (c) and AOPP (f) content of the controls, incidentaloma, pheochromocytoma, and Cushing's/Conn's adenoma patients. Results are presented as with minimum and maximum. ${ }^{*} p<0.05,{ }^{* *} p<0.01,{ }^{* * *} p<0.001$, and ${ }^{* * * *} p<0.0001$ indicate significant differences from the controls; $\wedge p<0.05$ indicates significant differences from the pheochromocytoma group.

DNA/RNA oxidation products (sensitivity 95\%; specificity 96.67\%). Moreover, plasma DNA/RNA oxidation products with high sensitivity (80\%) and specificity (80\%) differentiate patients with pheochromocytoma from those with Cushing's/Conn's adenoma.

3.15. Correlations. Correlations between the analyzed redox biomarkers and clinical parameters of studied groups are presented in the heat maps (Figure 7).

In the controls, serum aldosterone negatively correlated with urine CAT $(p=0.045, R=-0.26)$ and urine GSH-Px $(p=0.013, R=-0.319)$. Plasma redox status was associated negatively with serum GSH-PX ( $p=0.12, R=-0.493)$, plasma total glutathione $(\mathrm{p}=0.008, \mathrm{R}=-0.521)$, and plasma GSSG $(p<0.0001, R=-0.725)$, whereas positively with plasma GSH ( $p=0.001, R=0.64)$. Urine redox status correlated neg- atively with urine GSSG $(p<0.0001, R=-4.94)$ and positively with urine total glutathione $(p=0.008, R=0.337)$ and urine GSH ( $p<0.0001, R=0.938$ ). We found positive correlations between serum GR and plasma MDA $(p=0.006, R=0.349)$ and BMI ( $p=0.034, R=0.389$ ), plasma total glutathione and plasma GSH $(p=0.015, R=0.314)$ and plasma GSSG $(p<$ $0.0001, R=0.925)$, urine total glutathione, urine GSH $(p<$ $0.0001, R=0.618)$ and urine GSSG $(p<0.0001, R=0.613)$, and plasma GSSG and plasma UA ( $p=0.036, R=0.271)$, as well as serum cortisol, urine metanephrine $(p=0.012, R=$ $0.323)$, and urine normetanephrine $(p=0.023, R=0.293)$. The high positive correlation was also between urine metanephrine and urine normetanephrine $(p<0.0001, R=0.881)$. A negative correlation was also showed between plasma GSH and plasma RNA/DNA oxidation products $(p=0.014$, $R=-0.315)$, plasma $\mathrm{UA}$, urine metanephrine $(p=0.012$, 


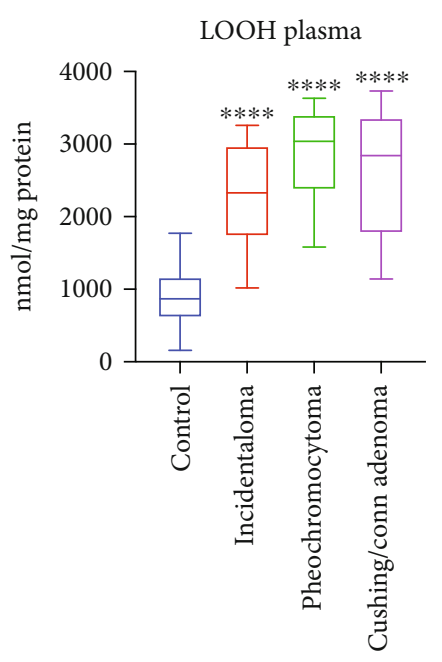

(a)

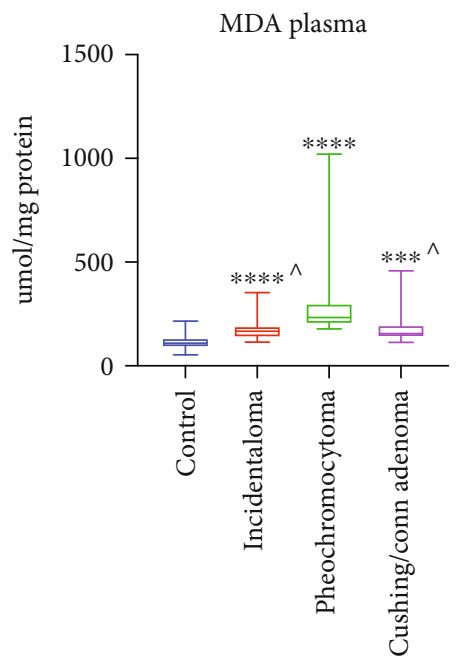

(d)

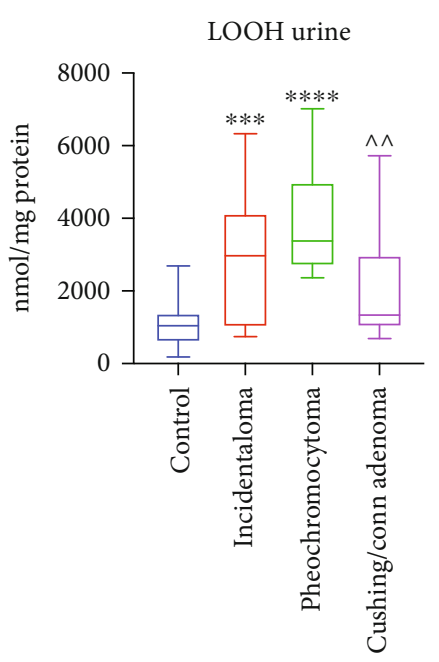

(b)

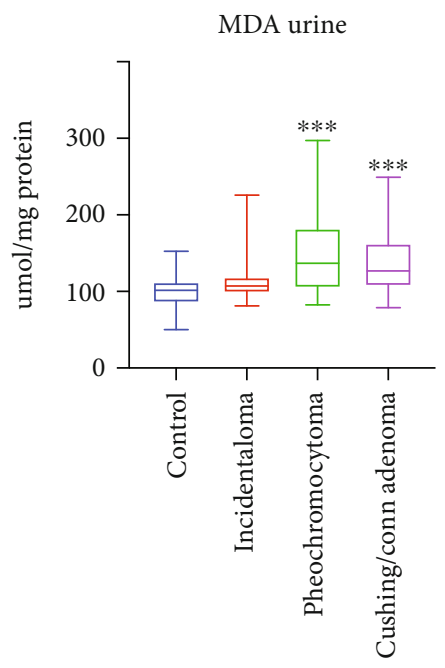

(e)

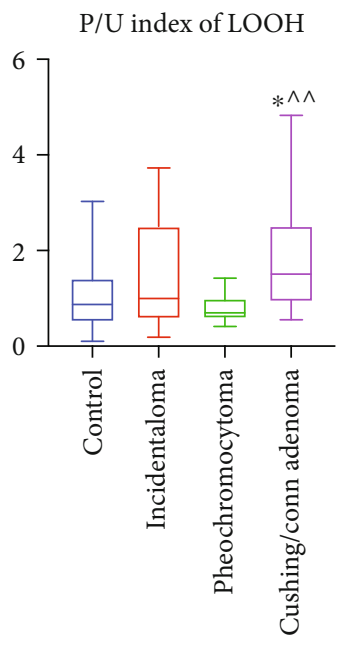

(c)

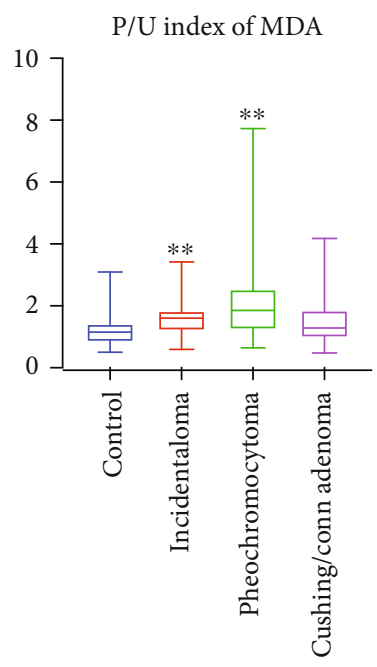

(f)

Figure 5: Plasma and urine concentration of lipid hydroperoxides (LOOH) (a, b) and malondialdehyde (MDA) (d, e), as well as plasma/urine index of LOOH (c) and MDA (f) concentration of the controls, incidentaloma, pheochromocytoma, and Cushing's/Conn's adenoma patients. Results are presented as median with minimum and maximum. ${ }^{*} p<0.05,{ }^{* *} p<0.01,{ }^{* * *} p<0.001$, and ${ }^{* * * *} p<0.0001$ indicate significant differences from the controls; $\wedge p<0.05$ and $\wedge \wedge p<0.01$ indicate significant differences from the pheochromocytoma group.

$R=-0.322)$, and urine normetanephrine $(p=0.018, R=$ $-0.303)$, as well as urine UA and urine AGE $(p=0.013, R=$ -0.318 ) (Figure 7(a)).

The incidentaloma group serum GSH-Px correlated positively with serum CAT $(p=0.032, R=0.392)$, plasma GSH ( $p=0.001, R=0.592)$, plasma redox status $(p=0.008$, $R=0.498)$, and urine metanephrine $(p=0.045, R=-0.368)$. Plasma GSH was associated positively with plasma redox status $(p<0.0001, R=0.846)$, plasma UA $(p=0.002, R=$ $0.547)$, and negatively with plasma AGE $(p=0.019, R=$ $-0.426)$. The positive correlations were observed between plasma redox status and plasma UA $(p=0.018, R=0.452)$, urine metanephrine $(p=0.021, R=0.442)$ and urine normetanephrine $(p<0.0001, R=0.719)$, urine MDA and serum glucose $(p=0.025, R=0.438)$, plasma AOPP and plasma LOOH ( $p=0.006, R=0.492)$, urine redox status and urine GSH $(p<0.0001, R=0.886)$, and urine total glutathione $(p=0.04, R=0.397)$. Additionally, urine total glutathione correlated positively with urine GSH $(p<0.0001, R=0.718)$, urine GSSG $(p=0.009, R=0.471)$, and urine UA $(p=0.047$, $R=0.366$ ). We also found positive correlations between plasma total glutathione and plasma GSH $(p=0.02, R=$ $0.423)$ and plasma GSSG $(p<0.0001, R=0.913)$, whereas the negative correlations were observed between urine GSH$\mathrm{Px}$ and urine RNA/DNA oxidation products $(p=0.044, R=$ $-0.37)$, plasma redox status and plasma AGE $(p=0.001$, $R=-0.6)$, and urine metanephrine and plasma $\operatorname{AGE}(p=$ $0.012, R=-0.454$ ) (Figure 7(b)).

In patients with pheochromocytoma, we observed that plasma redox status correlated positively with serum GSHPx $(p=0.001, R=0.669)$, serum GR $(p=0.008, R=0.576)$, plasma GSH $(p<0.0001, R=0.761)$, and plasma LOOH ( $p=0.025, R=0.501)$, while it correlated negatively with plasma GSSG $(p=0.015, R=-0.535)$ and urine normetanephrine $(p=0.023, R=-0.507)$. Interestingly, highly positive correlation was found between urine redox status and 


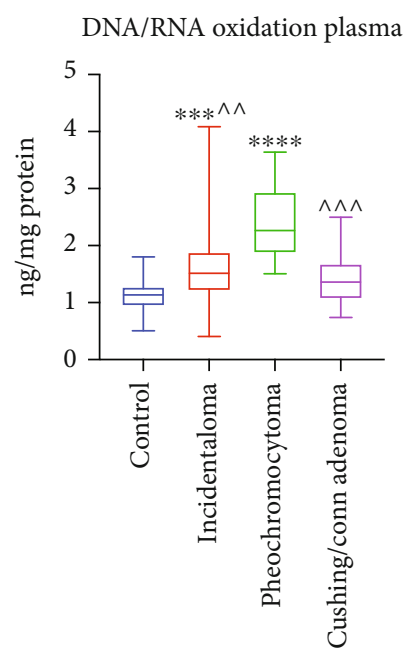

(a)

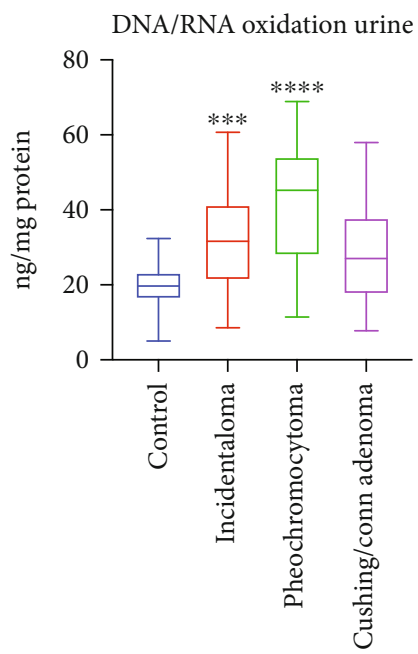

(b)

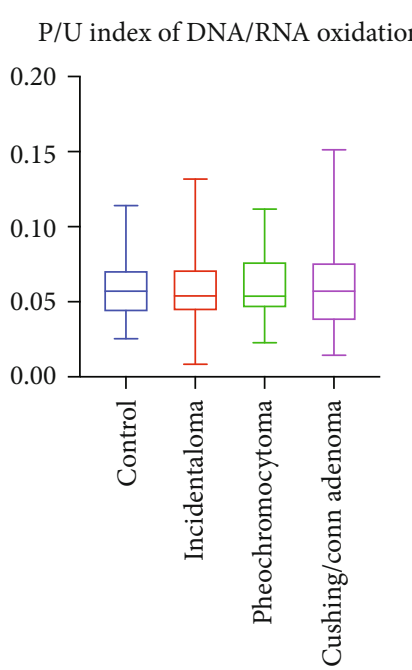

(c)

FIGURE 6: Plasma and urine DNA/RNA oxidation products ( $a, b)$ and plasma/urine index of DNA/RNA oxidation product content (c) of the controls, incidentaloma, pheochromocytoma, and Cushing's/Conn's adenoma patients. Results are presented as median with minimum and maximum. ${ }^{* * *} p<0.001$ and ${ }^{* * * *} p<0.0001$ indicate significant differences from the controls; $\wedge \wedge p<0.01$ and $\wedge \wedge \wedge p<0.001$ indicate significant differences from the pheochromocytoma group.

urine GSH $(p<0.0001, R=0.913)$ and urine SOD $(p=0.024$, $R=0.516)$, while negative correlation was identified between urine redox status and urine GSH-Px $(p=0.011, R=-0.572)$. Additionally, urine GSH-Px was associated negatively with urine SOD $(p<0.0001, R=-0.725)$ and urine GSH $(p=$ $0.019, R=-0.531)$. Negative correlations were also observed between serum GR and urine normetanephrine $(p=0.005$, $G=-0.597$ ), plasma GSH and urine normetanephrine $(p=0.045, R=-0.453)$, urine UA and urine MDA ( $p=$ 0.007, $R=-0.595)$, and urine UA and serum aldosterone $(p=0.024, R=-0.529)$. We found positive correlation between serum GR and serum SOD $(p=0.038, R=0.468)$ and plasma GSH $(p=0.023, R=0.507)$, as well as plasma total glutathione and plasma GSSG $(p<0.0001, R=0.886)$, whereas urine total glutathione correlated positively with urine GSSG $(p<0.0001, R=0.786)$ and urine RNA/DNA oxidation products $(p=0.032, R=0.48)$. The positive correlation were also identified between plasma GSH and plasma $\mathrm{LOOH}$ ( $p=0.005, R=0.603)$, urine GSSG and urine normetanephrine ( $p=0.032, R=0.48)$, urine RNA/DNA oxidative products and urine normetanephrine $(p=0.039, R=0.465)$, plasma AGE and urine metanephrine $(p=0.033, R=0.478)$. Moreover, urine metanephrine was associated positively with plasma and urine RNA/DNA oxidative products $(p<$ $0.0001, R=0.714 ; p=0.005, R=0.597)$ and urine normetanephrine $(p=0.014, R=0.541)$ (Figure $7(\mathrm{c})$ ).

In Cushing's/Conn's group, we found positive correlations between serum SOD and plasma GSSG $(p=0.026, R=0.498)$, urine SOD and serum glucose $(p=0.02, R=0.542)$, plasma GSH and plasma GSH-Px $(p<0.0001, R=0.785)$, serum GR and urine normetanephrine $(p=0.009, R=0.565)$, plasma total glutathione and plasma GSH $(p=0.038, R=0.468)$, plasma total glutathione and plasma GSSG $(p<0.0001, R=$ $0.749)$, and urine total glutathione and urine GSSG ( $p=$ $0.004, R=0.617$ ), as well as urine UA and urine RNA/DNA oxidative products $(p=0.001, R=0.662)$. Urine RNA/DNA oxidative products correlated positively with urine $\mathrm{LOOH}$ $(p=0.024, R=0.502)$. Plasma redox status was associated positively with GSH-Px $(p=0.002, R=0.674)$ and plasma GSH $(p<0.0001, R=0.798)$. Similarly, urine plasma redox status correlated highly positive with urine GSH $(p<$ $0.0001, R=0.974)$ and negative with urine GSSG ( $p=$ $0.001, R=-0.695)$. The negative correlations were observed between urine SOD and urine metanephrine $(p=0.042$, $R=-0.459$ ), plasma total glutathione and plasma RNA/DNA oxidative products $(p=0.029, R=-0.487)$, and urine metanephrine and BMI $(p=0.008, R=-0.571)$ (Figure $7(\mathrm{~d}))$.

\section{Discussion}

One of the most important factors involved in the development of neoplasms is oxidative stress. This process initiates DNA damage and leads to genetic mutations and chromosomal instability $[18,22,36]$. In biological systems, ROS play a dual role, both beneficial and harmful. ROS's positive effects include the cellular response against infectious agents and participation in cell signaling as messengers' factors. Low concentrations of free radicals also induce a mitogenic response [37, 38]. However, enhanced formation of ROS leads to oxidative damage to cellular structures, and therefore, disrupts the cell's metabolism. Indeed, ROS overproduction and altered regulation of redox-related signaling pathways have been observed in various types of cancer $[22,39]$. The carcinogenesis process is associated with DNA oxidative damage, which in turn results in replication errors, genome instability, and impaired signal transduction pathways $[40,41]$. This may be due to depletion of antioxidant reserves; although in some types of cancer, the antioxidant barrier is strengthened as an adaptive response to ROS overproduction [14-17]. Unfortunately, the role of the 


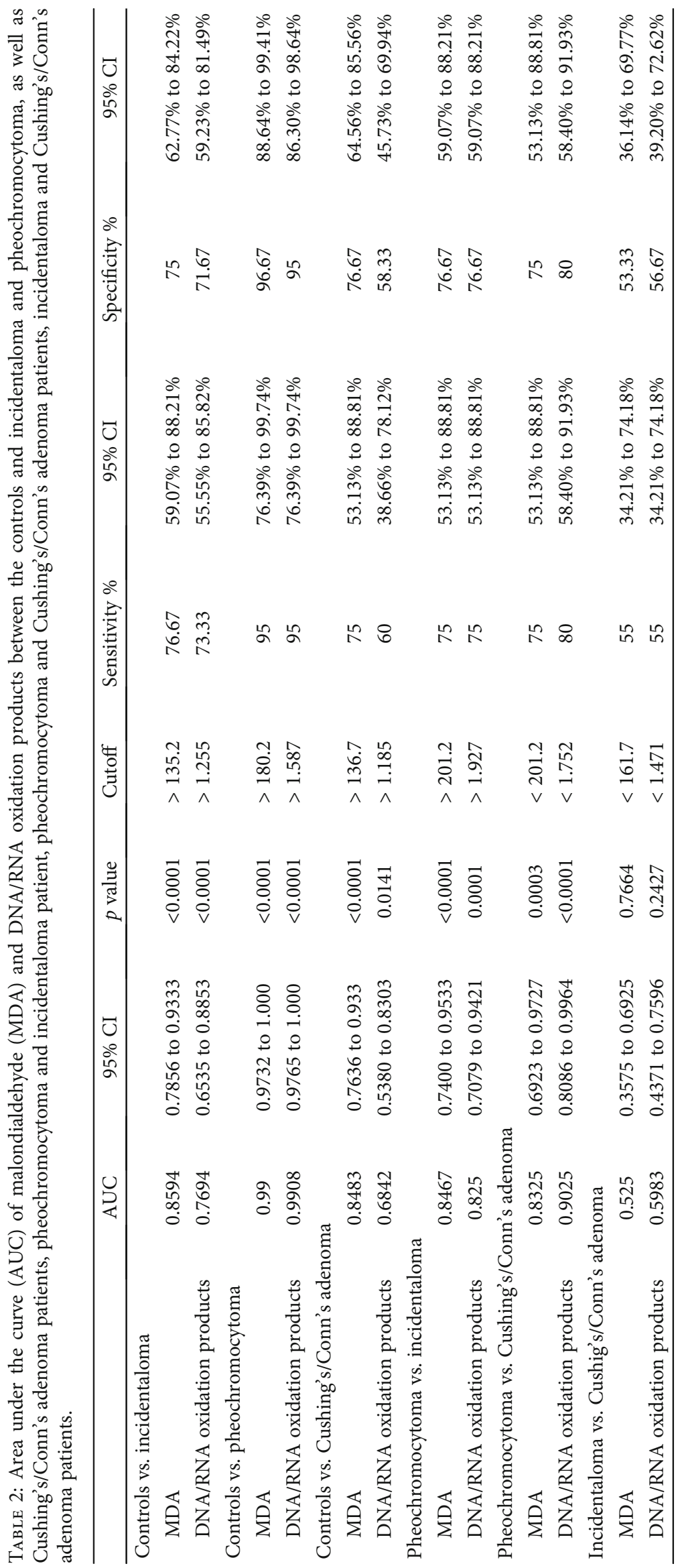




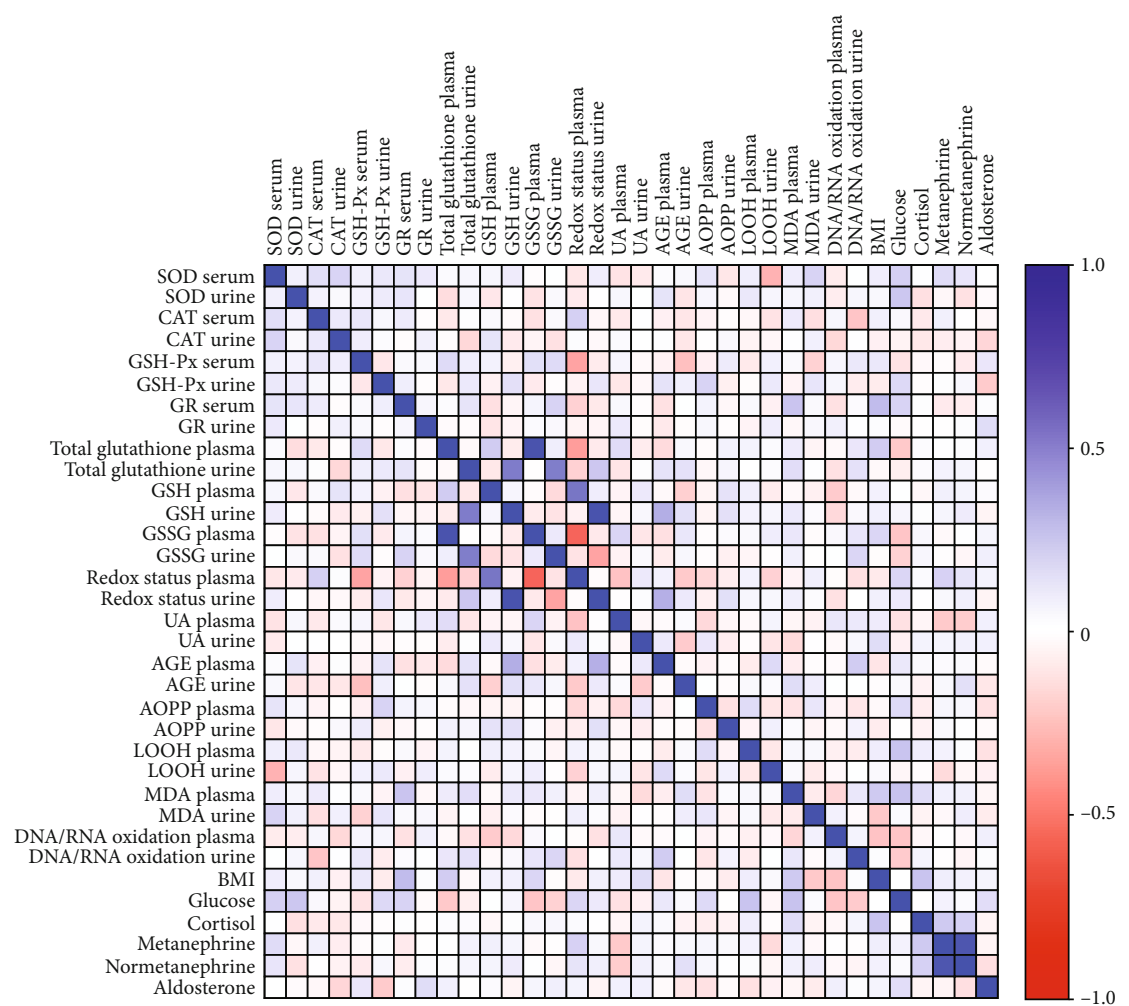

(a)

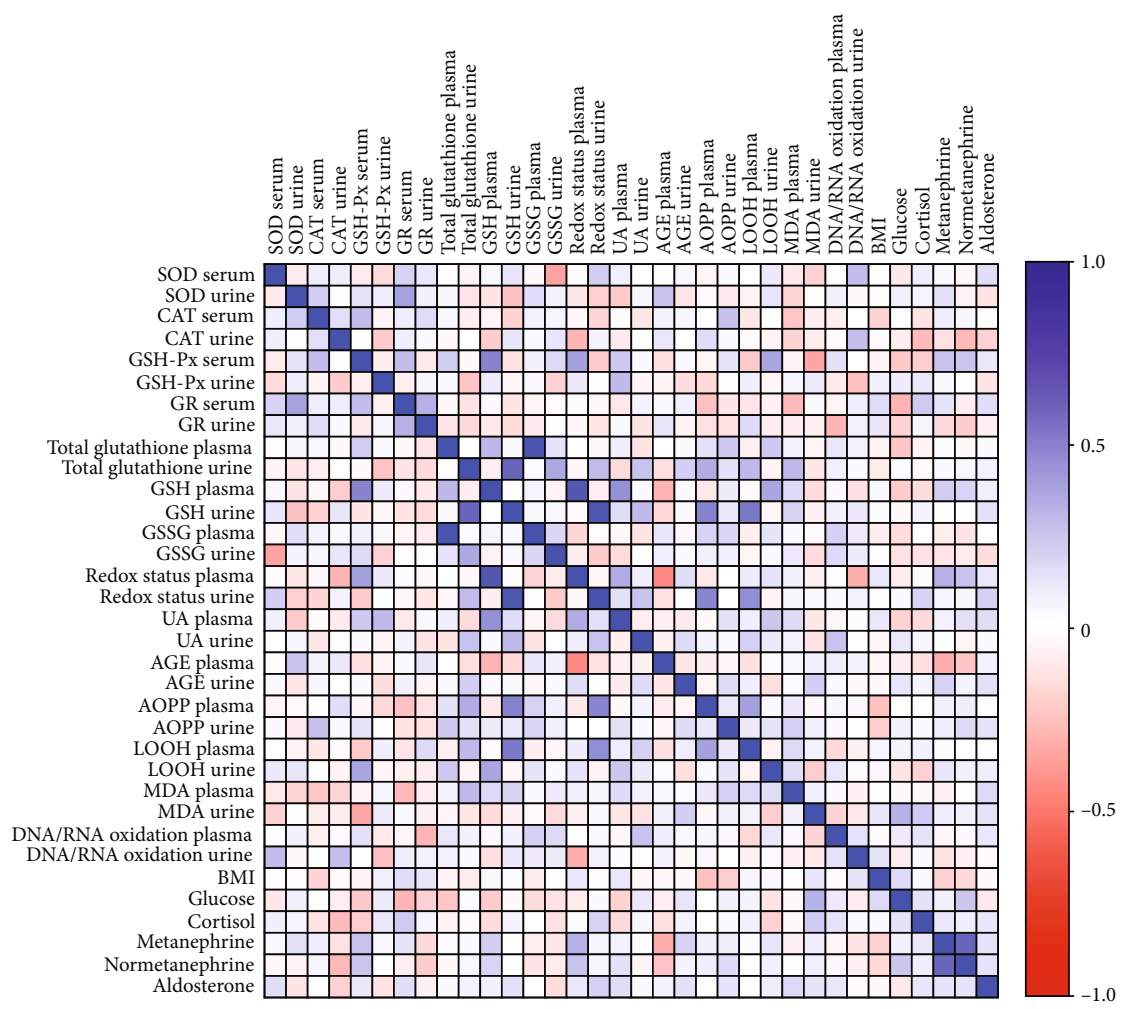

(b)

FIgURE 7: Continued. 


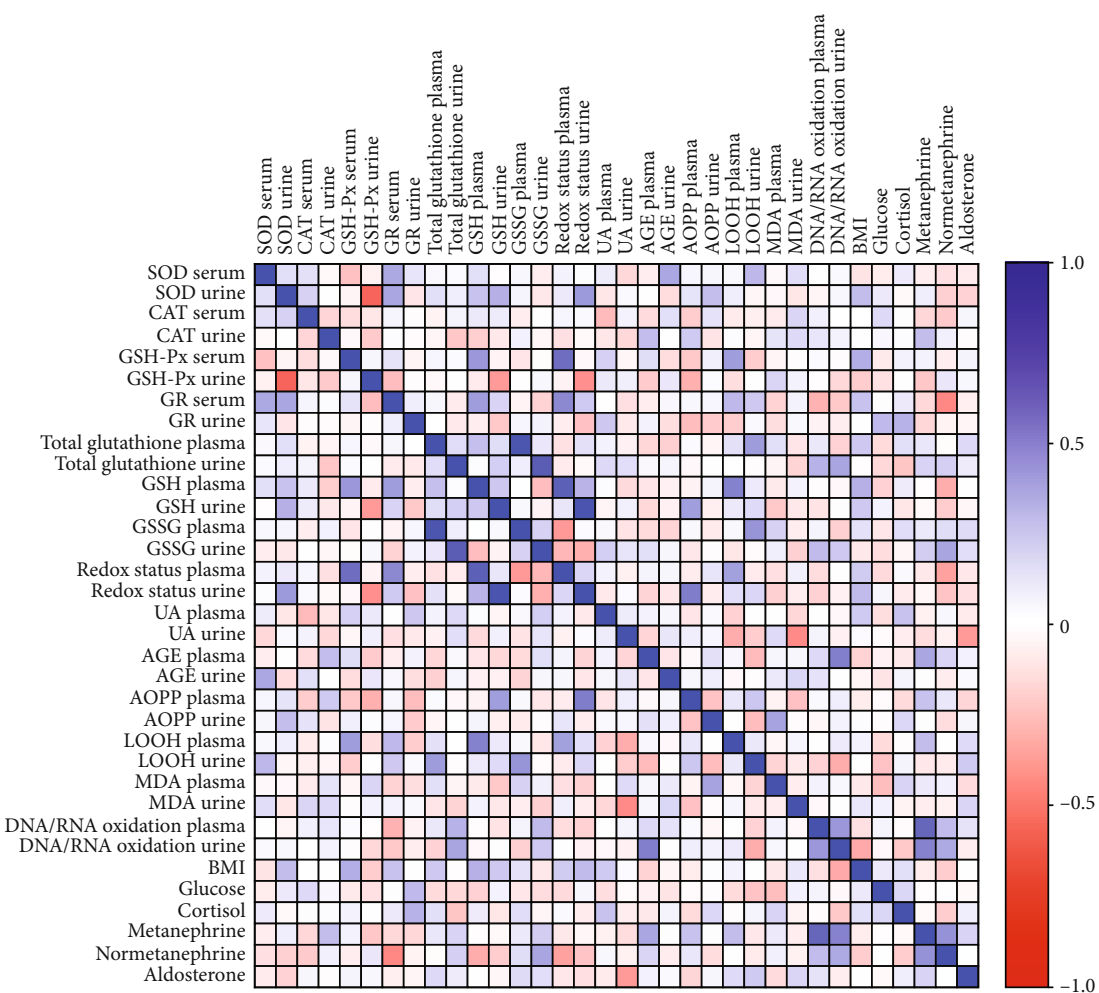

(c)

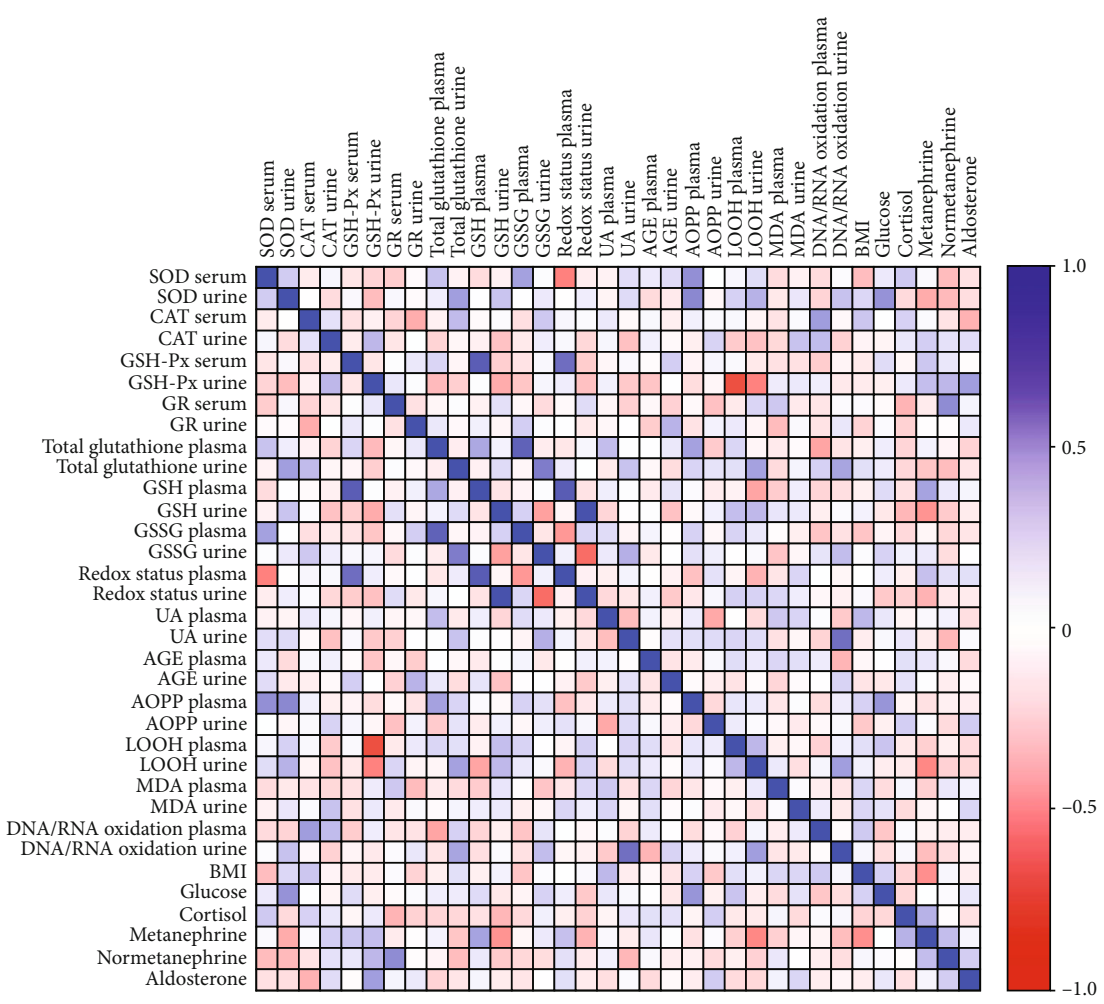

(d)

FIGURE 7: Correlations between the analyzed redox biomarkers and clinical parameters in serum, plasma, and urine of the controls (a) and patients with incidentaloma (b), pheochromocytoma (c), and Cushing's/Conn's adenoma (d). SOD: superoxide dismutase; CAT: catalase; GSH-Px: glutathione peroxidase; GR: glutathione reductase; GSH: glutathione; GSSG: glutathione disulfide; UA: uric acid; AGE: advanced glycation end products; AOPP: advanced oxidation protein products; LOOH: lipid hydroperoxides; MDA: malondialdehyde; BMI: body mass index. 
antioxidant barrier and oxidative stress is not completely understood in the context of adrenal tumors.

This is the first study evaluating the redox balance, glutathione metabolism, and oxidative damage to RNA/DNA, proteins, and lipids in the plasma/serum and urine of patients with adrenal masses. We demonstrated disturbances in enzymatic and nonenzymatic antioxidant barrier: serum SOD and CAT and plasma UA and GSH significantly decreased with simultaneous increases of blood GSH-Px and GSSG in patients with adrenal masses. Moreover, we observed a greater amount of oxidative damage products of RNA/DNA, proteins ( $\uparrow$ AGE, $\uparrow A O P P)$, and lipids ( $\uparrow \mathrm{LOOH}$, $\uparrow M D A)$ in the plasma and urine in these patients. Most redox biomarkers did not differentiate study groups: incidentaloma, pheochromocytoma, and Cushing's/Conn's adenoma. Nevertheless, we found that plasma RNA/DNA oxidation products could differentiate pheochromocytoma and Cushing's/Conn's adenoma with high specificity and sensitivity.

Cells of aerobic organisms have evolved many defense mechanisms to protect themselves from ROS overproduction. In our study, we generally showed a reduction in the antioxidant defense capacity (serum/plasma: $\downarrow$ SOD, $\downarrow$ CAT, $\downarrow$ GSH, $\downarrow$ UA; urine: $\downarrow$ SOD, $\downarrow$ GSH, $\downarrow$ UA), which may be responsible for the enhanced oxidation of proteins, lipids, and DNA at a systemic level. This can be confirmed by the negative correlation between plasma total glutathione and plasma RNA/DNA oxidative products, urinary GSH-Px and RNA/DNA oxidation, and plasma redox status and plasma AGEs. Of particular note is the decrease in GSH, the major intracellular nonenzymatic antioxidants, with a concomitant increase in its oxidized form (GSSG). Glutathione disulfide is highly toxic to the body because it enhances protein glutathiolation and induces cell death by apoptosis or necrosis. Thus, GSSG disrupts the thiol status of the cell affecting the regulation of gene transcription, enzyme activity, and expression of various cell receptors [42, 43]. Because the main defense mechanism against GSSG overload is its translocation outside the cells $[44,45]$, the increase in plasma oxidized glutathione may, in part, reflect glutathione metabolism in the cancer cell. Additionally, increased GSH-Px activity in pheochromocytoma patients with a concomitant decrease in CAT activity may indicate their compensatory action in inactivating hydrogen peroxide. $\mathrm{H}_{2} \mathrm{O}_{2}$ does not have a strong oxidizing effect directly, but it readily crosses cell membranes and, together with the superoxide radical, can be a source of the highly reactive hydroxyl radical [39, 46]. Hydrogen peroxide also plays a key role in the regulation of cell proliferation and cell death. Depending on its concentration, a cell can either divide or undergo apoptosis and necrosis [47]. Based on studies of other cancers, it has been suggested that cells with low SOD and CAT activity profile and with variable GSH-Px activity promote cancer tumor formation [48]. However, these mechanisms are not well understood, and there is a lack of any research in the context of adrenal tumors.

Oxidative stress is involved not only in the initiation and promotion of carcinogenesis but also in the tumor progression. Oxidative stress has been shown to increase inflamma- tion and cytokine activity $[13,17]$. It is also responsible for intense cancer cell metabolism associated with continuous tumor proliferation, mitochondrial DNA mutations, and mitochondrial dysfunction. Because the largest amounts of ROS are generated in the respiratory chain, the mitochondrial membrane is the most vulnerable to oxidation. As a result of this damage, cytochrome $\mathrm{c}$ is released, and the apoptotic cascade is activated $[49,50]$. Although most adrenal tumors are benign, it is still unclear whether they can become malignant and what factors may influence tumor metastasis. Although our study does not explain this, disturbances in the antioxidant barrier might promote or enhance the process of adrenal tissue transformation into a tumor [51]. Mechanisms responsible for enhancing cellular proliferation may include direct interaction of free radicals with specific receptors and modulation of the expression of important signaling agents, such as protein kinases and transcription factors $[51,52]$. In pheochromocytomas, the major genetic aberrations involve kinase signaling and protein translation genes $[53,54]$. It is well known that under oxidative stress conditions, there are upregulation of src/Abl kinase, PI3 kinase, and MAPK dependent signaling pathways as well as activation of redox-regulated transcription factors such as NF- $\kappa \mathrm{B}, \mathrm{AP}-1, \mathrm{p} 53$, NFAT, and HIF-1 [22]. In pheochromocytoma, the most common mutations occur in genes involved in the VHL/HIF axis, including PHD, VHL, and HIF [53]. HIFs are transcription factors that serve as major regulators of oxygen metabolism [55, 56]. They have various effects on tumor growth affecting cell proliferation, differentiation, vascularization, angiogenesis, tumor immune response, invasion, metastasis, and apoptosis [57]. HIFs are also the main transcription factors responding to hypoxia in the cell [58]. Interestingly, the increased HIF-1 $\alpha$ expression contributes to mitochondrial dysfunction and ROS overproduction [59-61]. Indeed, HIF-1 activation by stabilization of HIF- $1 \alpha$ upregulates NADPH oxidase, which is the main source of ROS in response to hypoxia [62, 63]. Reduced GSH levels increase the synthesis of inflammatory mediators (such as IL-1 $\beta$ and TNF- $\alpha$ ), which in turn induce the synthesis of HIF-1 $\alpha$ [64]. Although the involvement of HIF and oxidative stress in adrenal tumors seems to be important, our hypotheses need to be verified in further molecular studies.

Pheochromocytoma can be classified as a metabolic disease due to the increased secretion of catecholamines such as dopamine, adrenaline, and noradrenaline. Indeed, catecholamines are involved in the regulation of many metabolic pathways, and therefore, patients with phaeochromocytoma may have impaired glucose metabolism, insulin resistance, and lipid metabolism disorders $[65,66]$. Pheochromocytoma is also a secondary cause of diabetes mellitus, which, in some patients, may be the only clinical symptom of the tumor. Although adrenal tumors are responsible for various metabolic complications, serum glucose levels in our patients are generally within the reference range. The surgical removal of the cancer results in the remission of diabetes, emphasizing the pathogenic role of excess catecholamines $[67,68]$. Nevertheless, the development of insulin resistance in patients with adrenal tumors is not clear. This can be related 
to the decreased levels of adiponectin [69]. Another explanation may be a constant oxidative stress as suggested by our experiment. As many studies have confirmed the key role of redox imbalance in obesity, insulin resistance, and diabetes pathophysiology $[9,10,70]$, metabolic disorders in phaeochromocytoma may result from disturbances in antioxidant barrier and intensification of oxidative stress. This may be indicated by the positive correlation between plasma glucose and urinary MDA levels, as well as between metanephrine and BMI. Although catecholamines may show antioxidant and antiglycation properties, the accumulation of their oxidation products in tissues may have cytotoxic and mutagenic effects $[71,72]$. It has been shown that semiquinone radicals (formed in the oxidation of dopamine, epinephrine, and norepinephrine) cause glutathione oxidation as well as induce lipoperoxidation and oxidative DNA damage [73]. Catabolism of catecholamines (mediated by MAO and COMT enzymes) may also exacerbate oxidative stress level in the cell [73]. In general, the concentrations of protein, lipid, and DNA oxidation products were the highest in patients with pheochromocytoma (compared with other tumors), indicating that redox homeostasis is most disturbed in these group of patients. We cannot exclude that obesity and metabolic disorders are the source of impaired redox balance in our patients; however, the highest severity of oxidative stress was observed in patients with pheochromocytoma, in whom body weight is slightly elevated and glucose level is within the reference range.

The diagnosis of adrenal tumors requires complex studies; so in our study, we also decided to assess the markers of oxidative stress in the serum/plasma and urine as a material for research in an easily accessible and minimally invasive manner. It has recently been emphasized that oxidative stress plays a critical role in the pathogenesis of various diseases such as neurodegenerative diseases [74, 75], insulin resistance [76], diabetes [77, 78], hypertension [79, 80], metabolic syndrome [10, 81], stroke [82, 83], and cancer [84, 85]. Thus, we compared whether antioxidants/oxidation products can differentiate between patients with adrenal masses (incidentaloma, pheochromocytoma, and Cushing/Conn adenoma) as well as healthy controls. We have demonstrated that the assessment of plasma MDA and DNA/RNA oxidation products, with high sensitivity and specificity, can help to diagnose pheochromocytoma. Interestingly, plasma DNA/RNA oxidation products can differentiate patients with pheochromocytoma from Cushing/Conn adenoma patients as well as from healthy controls. The obtained correlations confirm the diagnostic usefulness of DNA/RNA oxidation products in patients with pheochromocytoma. Indeed, plasma RNA/DNA oxidative products were positively associated with urine metanephrine, whereas urine RNA/DNA oxidative products positively correlated with metanephrine and normetanephrine. Despite the observed changes in the urine redox biomarkers, we did not find them useful in diagnosing adrenal masses. This may be because the activity/concentration of antioxidants and oxidation products is significantly higher in plasma/serum than in urine, with the exception of DNA/RNA oxidation products, which are excreted via the renal route $[86,87]$.
The limitation of our study is that we have assessed redox homeostasis and oxidative stress only at the system level. Thus, in further research, it is necessary to evaluate molecular redox mechanisms in adrenal tumor development. Although oxidative stress in patients with adrenal tumors may be due to associated metabolic disorders, it is important to note that the primary cause of these abnormalities is the tumor. Nevertheless, this study is the first to assess redox balance, glutathione metabolism, and oxidative damage to RNA/DNA, proteins, and lipids in the plasma/serum and urine of patients with adrenal masses. It is also worth emphasizing that we have conducted studies on a relatively large number of patients, selectively divided on the type of adrenal tumor.

\section{Conclusions}

(1) Patients with adrenal tumors have impaired enzymatic and nonenzymatic antioxidant systems as well as increased oxidative damage to proteins, lipids, and DNA/RNA in both plasma, serum, and urine compared to controls. Antioxidant supplementation may be considered in patients with adrenal masses

(2) Plasma DNA/RNA oxidation products can differentiate patients with pheochromocytoma from Cushing's/Conn's adenoma as well as from healthy controls

(3) Oxidative stress may play a crucial role in adrenal tumors. Nevertheless, further studies are required to clarify the role of redox signaling in tumor development

\section{Data Availability}

The article contains complete data used to support the findings of this study.

\section{Conflicts of Interest}

The authors declare no conflict of interest.

\section{Authors' Contributions}

B.C., P.M., A.Z., and M.M. performed the conceptualization. B.C. performed the data curation. B.C. and M.M performed the formal analysis. B.C. and M.M. performed the funding acquisition. B.C., P.M., A.Z., and M.M. performed the investigation. B.C. and M.M. performed the methodology. B.C. performed the project administration. B.C., P.M., T.K., M.E, P.W., H.M., A.G., A.S, and J.D. contributed to the resources. B.C., P.M., K.C., and M.M. contributed to the software. P.M., M.Z.P., J.D. A.Z., and M.M. performed the supervision. B.C., K.C., and M.M. performed the validation. M.M performed the visualization. B.C. and M.M. contributed to the writing-original draft. P.M., A.Z. and M.M performed the writing-review and editing. All authors have read and agreed to the published version of the manuscript. 


\section{Acknowledgments}

This work was granted by the Medical University of Bialystok, Poland (grant number: SUB/1/DN/21/002/3330). Dr. Mateusz Maciejczyk was supported by the Foundation for Polish Science (FNP).

\section{References}

[1] G. Mansmann, J. Lau, E. Balk, M. Rothberg, Y. Miyachi, and S. R. Bornstein, "The clinically inapparent adrenal mass: update in diagnosis and management," Endocrine Reviews, vol. 25, no. 2, pp. 309-340, 2004.

[2] L. K. Nieman, "Approach to the patient with an adrenal incidentaloma," The Journal of Clinical Endocrinology and Metabolism, vol. 95, no. 9, pp. 4106-4113, 2010.

[3] J. H. Song and W. W. Mayo-Smith, "Incidentally discovered adrenal mass," Radiologic Clinics of North America, vol. 49, no. 2, pp. 361-368, 2011.

[4] W. F. Young, "The incidentally discovered adrenal mass," The New England Journal of Medicine, vol. 356, no. 6, pp. 601-610, 2007.

[5] J. Patrova, I. Jarocka, H. Wahrenberg, and H. Falhammar, "Clinical outcomes in adrenal incidentaloma: experience from one center," Endocrine Practice, vol. 21, no. 8, pp. 870-877, 2015.

[6] V. L. Martucci and K. Pacak, "Pheochromocytoma and paraganglioma: diagnosis, genetics, management, and treatment," Current Problems in Cancer, vol. 38, no. 1, pp. 7-41, 2014.

[7] I. R. Bhoster, H. G. Hill, and J. G. Greenfield, "The adrenogenital syndrome associated with cortical hyperplasia; the results of unilateral adrenalectomy," British Journal of Surgery, vol. 19, no. 76, pp. 557-570, 1932.

[8] J. M. Lee, M. K. Kim, S. H. Ko et al., "Clinical guidelines for the management of adrenal incidentaloma," Endocrinology and Metabolism, vol. 32, no. 2, pp. 200-218, 2017.

[9] B. Choromańska, P. Myśliwiec, M. Łuba et al., “A longitudinal study of the antioxidant barrier and oxidative stress in morbidly obese patients after bariatric surgery. Does the metabolic syndrome affect the redox homeostasis of obese people?," Journal of clinical medicine, vol. 9, no. 4, p. 976, 2020.

[10] B. Choromańska, P. Myśliwiec, M. Łuba et al., "The impact of hypertension and metabolic syndrome on Nitrosative stress and glutathione metabolism in patients with morbid obesity," Oxidative Medicine and Cellular Longevity, vol. 2020, Article ID 1057570, 10 pages, 2020.

[11] B. Choromańska, P. Myśliwiec, M. Łuba et al., "Impact of weight loss on the total antioxidant/oxidant potential in patients with morbid obesity-a longitudinal study," Antioxidants, vol. 9, no. 5, p. 376, 2020.

[12] B. Choromańska, P. Myśliwiec, M. Łuba et al., "Bariatric surgery normalizes protein glycoxidation and nitrosative stress in morbidly obese patients," Antioxidants, vol. 9, no. 11, p. 1087, 2020.

[13] S. Reuter, S. C. Gupta, M. M. Chaturvedi, and B. B. Aggarwal, "Oxidative stress, inflammation, and cancer: how are they linked?," Free Radical Biology \& Medicine, vol. 49, no. 11, pp. 1603-1616, 2010.

[14] J. Zińczuk, M. Maciejczyk, K. Zaręba et al., "Pro-oxidant enzymes, redox balance and oxidative damage to proteins, lipids and DNA in Colorectal cancer tissue. Is oxidative stress dependent on tumour budding and inflammatory infiltration?," Cancers (Basel), vol. 12, no. 6, p. 1636, 2020.

[15] J. E. Klaunig, L. M. Kamendulis, and B. A. Hocevar, "Oxidative stress and oxidative damage in carcinogenesis," Toxicologic Pathology, vol. 38, no. 1, pp. 96-109, 2010.

[16] D. Trachootham, J. Alexandre, and P. Huang, "Targeting cancer cells by ROS-mediated mechanisms: a radical therapeutic approach?," Nature Reviews. Drug Discovery, vol. 8, no. 7, pp. 579-591, 2009.

[17] S. Mena, A. Ortega, and J. M. Estrela, "Oxidative Stress in Environmental-Induced Carcinogenesis," Mutation Research/Genetic Toxicology and Environmental Mutagenesis, vol. 674, no. 1-2, pp. 36-44, 2009.

[18] M. Valko, D. Leibfritz, J. Moncol, M. T. D. Cronin, M. Mazur, and J. Telser, "Free radicals and antioxidants in normal physiological functions and human disease," The International Journal of Biochemistry \& Cell Biology, vol. 39, no. 1, pp. 4484, 2007.

[19] P. Poprac, K. Jomova, M. Simunkova, V. Kollar, C. J. Rhodes, and M. Valko, "Targeting free radicals in oxidative stressrelated human diseases," Trends in Pharmacological Sciences, vol. 38, no. 7, pp. 592-607, 2017.

[20] M. Maciejczyk, E. Heropolitanska-Pliszka, B. Pietrucha et al., "Antioxidant defense, redox homeostasis, and oxidative damage in children with ataxia telangiectasia and Nijmegen breakage syndrome," Frontiers in Immunology, vol. 10, p. 2322, 2019.

[21] B. Friguet, "Oxidized protein degradation and repair in ageing and oxidative stress," FEBS Letters, vol. 580, no. 12, pp. 29102916, 2006.

[22] M. Valko, C. J. Rhodes, J. Moncol, M. Izakovic, and M. Mazur, "Free radicals, metals and antioxidants in oxidative stressinduced cancer," Chemico-Biological Interactions, vol. 160, no. 1, pp. 1-40, 2006.

[23] K. Morawska, M. Maciejczyk, Ł. Popławski, A. PopławskaKita, A. Krętowski, and A. Zalewska, "Enhanced salivary and general oxidative stress in Hashimoto's thyroiditis women in euthyreosis," Journal of Clinical Medicine, vol. 9, no. 7, p. 2102, 2020.

[24] M. Maciejczyk, K. Taranta-Janusz, A. Wasilewska, A. Kossakowska, and A. Zalewska, "A case-control study of salivary redox homeostasis in hypertensive children. Can salivary uric acid be a marker of hypertension?," Journal of clinical medicine, vol. 9, no. 3, p. 837, 2020.

[25] H. P. Misra and I. Fridovich, "The role of superoxide anion in the autoxidation of epinephrine and a simple assay for superoxide dismutase," The Journal of Biological Chemistry, vol. 247, no. 10, pp. 3170-3175, 1972.

[26] H. Aebi, "[13] Catalase in vitro," Oxygen Radicals in Biological Systems, vol. 105, pp. 121-126, 1984.

[27] D. E. Paglia and W. N. Valentine, "Studies on the quantitative and qualitative characterization of erythrocyte glutathione peroxidase," The Journal of Laboratory and Clinical Medicine, vol. 70, no. 1, pp. 158-169, 1967.

[28] C. E. Mize and R. G. Langdon, "Hepatic glutathione reductase: I. Purification and general kinetic properties," The Journal of Biological Chemistry, vol. 237, no. 5, pp. 1589-1595, 1962.

[29] M. Moron, J. Depierre, and B. Mannervik, "Levels of glutathione, glutathione reductase and glutathione _S_ -transferase activities in rat lung and liver," Biochimica et Biophysica Acta (BBA) - General Subjects, vol. 582, no. 1, pp. 67-78, 1979. 
[30] A. Zalewska, D. Ziembicka, M. Żendzian-Piotrowska, and M. Maciejczyk, "The impact of high-fat diet on mitochondrial function, free radical production, and nitrosative stress in the salivary glands of Wistar rats," Oxidative Medicine and Cellular Longevity, vol. 2019, Article ID 2606120, 15 pages, 2019.

[31] J. A. Buege and S. D. Aust, "[30] Microsomal lipid peroxidation," Methods in Enzymology, vol. 52, pp. 302-310, 1978.

[32] J. Nourooz-Zadeh, J. Tajaddini-Sarmadi, and S. P. Wolff, "Measurement of hydroperoxides in edible oils using the ferrous oxidation in xylenol orange assay," Journal of Agricultural and Food Chemistry, vol. 43, no. 1, pp. 17-21, 1995.

[33] A. Skutnik-Radziszewska, M. Maciejczyk, I. Flisiak et al., "Enhanced inflammation and Nitrosative stress in the saliva and plasma of patients with plaque psoriasis," Journal of Clinical Medicine, vol. 9, no. 3, p. 745, 2020.

[34] M. Kalousová, J. Skrha, and T. Zima, "Advanced glycation end-products and advanced oxidation protein products in patients with diabetes mellitus," Physiological Research, vol. 51, no. 6, pp. 597-604, 2002.

[35] M. Maciejczyk, A. Skutnik-Radziszewska, I. Zieniewska et al., "Antioxidant defense, oxidative modification, and salivary gland function in an early phase of cerulein pancreatitis," Oxidative Medicine and Cellular Longevity, vol. 2019, Article ID 8403578, 14 pages, 2019.

[36] P. D. Ray, B. W. Huang, and Y. Tsuji, "Reactive oxygen species (ROS) homeostasis and redox regulation in cellular signaling," Cellular Signalling, vol. 24, no. 5, pp. 981-990, 2012.

[37] M. L. Circu and T. Y. Aw, "Reactive oxygen species, cellular redox systems, and apoptosis," Free Radical Biology \& Medicine, vol. 48, no. 6, pp. 749-762, 2010.

[38] V. I. Lushchak, "Free radicals, reactive oxygen species, oxidative stress and its classification," Chemico-biological interactions, vol. 224, pp. 164-175, 2014.

[39] G. Poli, G. Leonarduzzi, F. Biasi, and E. Chiarpotto, "Oxidative stress and cell Signalling," Current Medicinal Chemistry, vol. 11, no. 9, pp. 1163-1182, 2004.

[40] M. S. Cooke, M. D. Evans, M. Dizdaroglu, and J. Lunec, "Oxidative DNA damage: mechanisms, mutation, and disease," The FASEB Journal, vol. 17, no. 10, pp. 1195-1214, 2003.

[41] M. Maciejczyk, B. Mikoluc, B. Pietrucha et al., "Oxidative stress, mitochondrial abnormalities and antioxidant defense in Ataxiatelangiectasia, Bloom syndrome and Nijmegen breakage syndrome," Redox Biology, vol. 11, pp. 375-383, 2017.

[42] R. O. Species, T. Finkel, and R. O. Species, "Reactive oxygen species and signal transduction," IUBMB Life, vol. 52, no. 1, pp. 3-6, 2001.

[43] K. Aquilano, S. Baldelli, and M. R. Ciriolo, "Glutathione: New roles in redox signaling for an old antioxidant," Frontiers in pharmacology, vol. 5, 2014.

[44] J. Borys, M. Maciejczyk, B. Antonowicz et al., "Glutathione metabolism, mitochondria activity, and nitrosative stress in patients treated for mandible fractures," Journal of Clinical Medicine, vol. 8, no. 1, p. 127, 2019.

[45] Y. Liu, A. S. Hyde, M. A. Simpson, and J. J. Barycki, "Emerging regulatory paradigms in glutathione metabolism," Advances in Cancer Research, vol. 122, pp. 69-101, 2014.

[46] E. Żebrowska, M. Maciejczyk, M. Żendzian-Piotrowska, A. Zalewska, and A. Chabowski, "High protein diet induces oxidative stress in rat cerebral cortex and hypothalamus,"
International journal of molecular sciences, vol. 20, no. 7, p. $1547,2019$.

[47] B. J. Day, "Catalase and glutathione peroxidase mimics," Biochemical Pharmacology, vol. 77, no. 3, pp. 285-296, 2009.

[48] Y. Sun, "Free radicals, antioxidant enzymes, and carcinogenesis," Free Radical Biology \& Medicine, vol. 8, no. 6, pp. 583599, 1990.

[49] M. Maciejczyk, E. Żebrowska, and A. Chabowski, "Insulin resistance and oxidative stress in the brain: What's new?," International journal of molecular sciences, vol. 20, no. 4, p. 874, 2019.

[50] M. Ott, V. Gogvadze, S. Orrenius, and B. Zhivotovsky, "Mitochondria, oxidative stress and cell death," Apoptosis, vol. 12, no. 5, pp. 913-922, 2007.

[51] G. Barrera, "Oxidative stress and lipid peroxidation products in cancer progression and therapy," International Scholarly Research Notices, vol. 2012, Article ID 242850, 21 pages, 2012.

[52] S. Pizzimenti, C. Toaldo, P. Pettazzoni, M. U. Dianzani, and G. Barrera, "The "two-faced" effects of reactive oxygen species and the lipid peroxidation product 4-Hydroxynonenal in the hallmarks of cancer," Cancers (Basel), vol. 2, no. 2, pp. 338363,2010 .

[53] L. Fishbein, I. Leshchiner, V. Walter et al., "Comprehensive molecular characterization of pheochromocytoma and paraganglioma," Cancer Cell, vol. 31, no. 2, pp. 181-193, 2017.

[54] J. Crona, D. Taïeb, and K. Pacak, "New perspectives on pheochromocytoma and paraganglioma: toward a molecular classification," Endocrine Reviews, vol. 38, no. 6, pp. 489515, 2017.

[55] G. L. Semenza, "Defining the role of hypoxia-inducible factor 1 in cancer biology and therapeutics," Oncogene, vol. 29, no. 5, pp. 625-634, 2010.

[56] I. Jochmanová, T. Zelinka, J. Widimský Jr., and K. Pacak, "HIF signaling pathway in pheochromocytoma and other neuroendocrine tumors," Physiological Research, vol. 63, Supplement 2, pp. S251-S262, 2014

[57] C. Wigerup, S. Påhlman, and D. Bexell, “Therapeutic targeting of hypoxia and hypoxia-inducible factors in cancer," Pharmacology \& Therapeutics, vol. 164, pp. 152-169, 2016.

[58] K. Błaszczak-Świątkiewicz, P. Olszewska, and E. MikiciukOlasik, "Wpływ hipoksji na zmiany metabolizmu komórek nowotworowych," NOWOTWORY Journal of Oncology, vol. 62, no. 4, pp. 283-290, 2012.

[59] F. H. Agani, P. Pichiule, J. C. Chavez, and J. C. LaManna, "The role of mitochondria in the regulation of hypoxia-inducible factor 1 expression during hypoxia," The Journal of Biological Chemistry, vol. 275, no. 46, pp. 35863-35867, 2000.

[60] N. S. Chandel, D. S. McClintock, C. E. Feliciano et al., "Reactive oxygen species generated at mitochondrial complex III stabilize hypoxia-inducible factor- $1 \alpha$ during hypoxia:," The Journal of Biological Chemistry, vol. 275, no. 33, pp. 25130 25138, 2000.

[61] C. Schroedl, D. S. McClintock, G. R. S. Budinger, and N. S. Chandel, "Hypoxic but not anoxic stabilization of HIF- $1 \alpha$ requires mitochondrial reactive oxygen species," American Journal of Physiology-Lung Cellular and Molecular Physiology, vol. 283, no. 5, pp. L922-L931, 2002.

[62] M. Zhang, J. Wu, L. Huo et al., "Environmental enrichment prevent the juvenile hypoxia-induced developmental loss of parvalbumin-immunoreactive cells in the prefrontal cortex and neurobehavioral alterations through inhibition of 
NADPH oxidase-2-derived oxidative stress," Molecular Neurobiology, vol. 53, no. 10, pp. 7341-7350, 2016.

[63] P. Liu, H. M. Zhang, K. Hu, X. F. Zhou, and S. Tang, "Sensory plasticity of carotid body is correlated with oxidative stress in paraventricular nucleus during chronic intermittent hypoxia," Journal of Cellular Physiology, vol. 234, no. 8, pp. 1353413543, 2019.

[64] J. Westra, E. Brouwer, R. Bos et al., "Regulation of cytokineinduced HIF-1 Expression in rheumatoid synovial fibroblasts," Annals of the New York Academy of Sciences, vol. 1108, no. 1, pp. 340-348, 2007.

[65] Z. Erlic and F. Beuschlein, "Metabolic alterations in patients with Pheochromocytoma," Experimental and Clinical Endocrinology \& Diabetes, vol. 127, pp. 129-136, 2019.

[66] A. William Tank and D. Lee Wong, "Peripheral and central effects of circulating catecholamines," Comprehensive Physiology, vol. 1, pp. 1-15, 2014.

[67] T. Beninato, W. P. Kluijfhout, F. T. Drake et al., "Resection of pheochromocytoma improves diabetes mellitus in the majority of patients," Annals of Surgical Oncology, vol. 24, no. 5, pp. 1208-1213, 2017.

[68] C. TONG, P. ENGLAND, P. CHAMPION de CRESPIGNY, R. MILLAR, and J. CONN, "Diabetes mellitus as the only manifestation of occult phaeochromocytoma prior to acute haemorrhage in pregnancy," The Australian \& New Zealand journal of obstetrics \& gynaecology, vol. 45, no. 1, pp. 91-92, 2005.

[69] Y. Okauchi, C. Ishibashi, K. Shu, S. Adachi, and I. Mineo, "Decreased serum adiponectin level during catecholamine crisis in an obese patient with pheochromocytoma," Internal Medicine, vol. 57, no. 9, pp. 1253-1257, 2018.

[70] R. Barazzoni, G. Gortan Cappellari, M. Ragni, and E. Nisoli, "Insulin resistance in obesity: an overview of fundamental alterations," Eating and Weight Disorders, vol. 23, no. 2, pp. 149-157, 2018.

[71] T. Shimizu, Y. Nakanishi, M. Nakahara et al., "Structure effect on antioxidant activity of catecholamines toward singlet oxygen and other reactive oxygen species in vitro," Journal of Clinical Biochemistry and Nutrition, vol. 47, no. 3, pp. 181-190, 2010.

[72] I. Gülçin, "Antioxidant activity of l-adrenaline: a structureactivity insight," Chemico-Biological Interactions, vol. 179, no. 2-3, pp. 71-80, 2009.

[73] A. G. Siraki and P. J. O'Brien, "Prooxidant activity of free radicals derived from phenol-containing neurotransmitters," Toxicology, vol. 177, no. 1, pp. 81-90, 2002.

[74] M. Maciejczyk, A. Zalewska, and K. Gerreth, "Salivary redox biomarkers in selected neurodegenerative diseases," Journal of Clinical Medicine, vol. 9, no. 2, p. 497, 2020.

[75] A. Klimiuk, M. Maciejczyk, M. Choromańska, K. Fejfer, N. Waszkiewicz, and A. Zalewska, "Salivary redox biomarkers in different stages of dementia severity," Journal of Clinical Medicine, vol. 8, no. 6, p. 840, 2019.

[76] E. J. Henriksen, M. K. Diamond-Stanic, and E. M. Marchionne, "Oxidative stress and the etiology of insulin resistance and type 2 diabetes," Free Radical Biology \& Medicine, vol. 51, no. 5, pp. 993-999, 2011.

[77] S. Spahis, J. M. Borys, and E. Levy, "Metabolic syndrome as a multifaceted risk factor for oxidative stress," Antioxidants \& redox signaling, vol. 26, no. 9, pp. 445-461, 2017.

[78] B. K. Tiwari, K. B. Pandey, A. B. Abidi, and S. I. Rizvi, "Markers of oxidative stress during diabetes mellitus," Journal of biomarkers, vol. 2013, Article ID 378790, 8 pages, 2013.
[79] N. Escobales and M. Crespo, "Oxidative-nitrosative stress in hypertension," Current Vascular Pharmacology, vol. 3, no. 3, pp. 231-246, 2005.

[80] R. Rodrigo, M. Libuy, F. Feliú, and D. Hasson, "Oxidative Stress-Related Biomarkers in Essential Hypertension and Ischemia- Reperfusion Myocardial Damage," Disease markers, vol. 35, no. 6, Article ID 974358, 790 pages, 2013.

[81] A. Zalewska, A. Kossakowska, K. Taranta-Janusz et al., "Dysfunction of salivary glands, disturbances in salivary antioxidants and increased oxidative damage in saliva of overweight and obese adolescents," Journal of Clinical Medicine, vol. 9, no. 2, p. 548, 2020.

[82] P. Gerreth, M. Maciejczyk, A. Zalewska, K. Gerreth, and K. Hojan, "Comprehensive evaluation of the oral health status, salivary gland function, and oxidative stress in the saliva of patients with subacute phase of stroke: a case-control study," Journal of Clinical Medicine, vol. 9, no. 7, p. 2252, 2020.

[83] A. Cherubini, C. Ruggiero, M. C. Polidori, and P. Mecocci, "Potential markers of oxidative stress in stroke," Free Radical Biology \& Medicine, vol. 39, no. 7, pp. 841-852, 2005.

[84] B. Sawczuk, M. Maciejczyk, M. Sawczuk-Siemieniuk, R. Posmyk, A. Zalewska, and H. Car, "Salivary gland function, antioxidant defence and oxidative damage in the saliva of patients with breast cancer: does the BRCA1 mutation disturb the salivary redox profile?," Cancers (Basel), vol. 11, no. 10, p. 1501, 2019.

[85] J. Zińczuk, M. Maciejczyk, K. Zaręba et al., "Antioxidant barrier, redox status, and oxidative damage to biomolecules in patients with colorectal cancer. Can malondialdehyde and catalase be markers of colorectal cancer advancement?" Biomolecules, vol. 9, no. 10, p. 637, 2019.

[86] S. Kanvah, J. Joseph, G. B. Schuster, R. N. Barnett, C. L. Cleveland, and U. Z. I. Landman, "Oxidation of DNA: damage to nucleobases," Accounts of Chemical Research, vol. 43, no. 2, pp. 280-287, 2010.

[87] M. E. Erdemli, E. Zayman, Z. Erdemli, M. Gul, S. Gul, and H. Gozukara Bag, "Protective effects of melatonin and vitamin E in acetamiprid-induced nephrotoxicity," Environmental Science and Pollution Research, vol. 27, no. 9, pp. 9202-9213, 2020. 